Documento No. 28

La Demanda de Dinero en México:

Primeras Estimaciones

por

Guillermo Ortiz

Septiembre, 1980

$\underline{\text { Las ideas contenidas en el presente ensayo son responsabilidad exclusiva del autor y no reflejan la }}$ posición del Banco de México, S.A. 


\title{
LA DEMANDA DE DINERO EN MEXICO: PRIMERAS ESTIMACIONES
}

\author{
por \\ Guillermo Ortiz *
}

Introducción.

La demanda de dinero es una de las relaciones macroeconómicas que más se han investigado empíricamente en las últimas tres décadas, sobre todo en países industrializados. La evidencia existente para países en desarrollo, aunque desde luego menos abundante, también se ha ido incrementando considerablemente a últimas fechas. Concretamente, en el caso de México existen varios trabajos que incluyen estimaciones econométricas de la demanda de dinero para distintos períodos de tiempo, algunos de ellos elaborados en fechas muy recientes. Vale la pena preguntarse, entonces, si se justifica un nuevo trabajo sobre el tema.

Un aspecto importante que diferencia los resultados de este documento de los obtenidos en trabajos previos es la base de datos utilizadas que cubre el período de 1960 a 1979 con observaciones trimestrales. La mayor parte de las estimaciones realizadas por otros autores utilizan datos anuales, y las que se basan en datos trimestrales cubren períodos de tiempo más reducidos ${ }^{1 /}$. Por otra parte, se ensayaron diversas especificaciones de la función de demanda, se buscó la definición de dinero más apropiada, y se incluyeron variables que corresponden a distintos modelos teóricos. Asimismo, se efectuaron pruebas de cambio estructural para detectar inestabilidades en el comportamiento de la función de demanda.

El documento está dividido en cuatro secciones. La primera incluye un breve resumen de los principales enfoques teóricos sobre demanda de dinero, y una discusión sobre el tipo de ecuaciones de estimación a las que dan lugar dichos modelos. En la segunda sección se hace una breve reseña crítica

Agradezo la muy extensa y competente colaboración de Patricia Abreu a lo largo de todo el trabajo, la ayuda de Donaciano Quintero y Víctor J. Pérez, y los comentarios de Armando Baqueiro y Gerardo Valdez. 
de los estudios previos de demanda de dinero para México en la que se comparan metodología y resultados. La tercera sección contiene un resumen de las estimaciones efectuadas y, por último, en la cuarta parte se presentan las conclusiones.

\section{Aspectos Teóricos y Empíricos.}

Existe una muy amplia literatura sobre prácticamente todos los aspectos tanto teóricos como empíricos relativos a la demanda de dinero. También se han publicado recientemente varios trabajos que reseñan dicha literatura, por lo que aquí sólo nos ocuparemos de tratar tres puntos concretos ${ }^{\underline{2}}$. El primero es ubicar la importancia que tiene la investigación sobre la demanda de dinero para países en desarrollo, y más concretamente para México. El segundo es establecer brevemente cuales han sido los enfoques teóricos principales sobre el tema para, en tercer lugar, discutir el tipo de formulaciones empíricas más usuales a que han dado lugar dichos enfoques.

\subsection{La Demanda de Dinero y la Política Monetaria.}

El gran numero de trabajos que sobre demanda de dinero se han producido a lo largo de los últimos veinte años obedece, seguramente, a la importancia central que tiene esta relación en el modelo post-Keynesiano de Hicks-Hansen (IS-LM). Este modelo, como es bien sabido, sirvió de marco teórico a la discusión entre keynesianos y monetaristas sobre la efectividad de las políticas monetaristas y fiscales en los años cincuentas y sesentas.

Hacia finales de la década de los sesenta, y después de acalorados debates, parecía que por fin se había llegado a un acuerdo sobre los puntos importantes que constituían las diferencias entre los enfoques monetarista y keynesiano, y que estas diferencias se podrían resolver empíricamente ${ }^{\underline{3} /}$. Uno de dichos puntos incluía, precisamente, el comportamiento de la demanda de dinero con respecto a la tasa de interés (que determina la pendiente de la curva LM), y el grado de homogeneidad de esta función con respecto a precios (grado de ilusión monetaria y su impacto en la curva de Phillips).

1/ Excepto el de G. Valdez (1980) que se reseña brevemente en la sección correspondiente, en el Apéndice Estadístico se detalla la metodología utilizada para la construcción de las series empleadas en las estimaciones.

2/ El ya clásico libro de Laidler (1977) contiene una excelente introducción y una reseña bastante completa.

3/ Véase el volumen editado por Gordon (1974); especialmente las contribuciones de Friedman, Tobin y Patinkin. 
En la medida que se pudiera precisar el grado de estabilidad de la demanda de dinero, y la sensibilidad del gasto privado a movimientos de la tasa de interés, se lograrían atenuar (por lo menos desde un punto de vista teórico) los ciclos económicos y asegurar un crecimiento sostenido. Esta fue la época (los sesenta) en que se desarrollaron los grandes modelos macroeconómicos en países industriales que permiten simular políticas económicas alternativas, y predecir el resultado de la aplicación de las mismas. Esta fue la época, también, en que existía un marcado optimismo en el funcionamiento de las herramientas de control macroeconómico, y que llevó a mas de un economista destacado a predecir que la época de los ciclos económicos había concluido.

Mas adelante, cuando los cambios operados en la economía mundial en los primeros años de los sesenta pusieron en entredicho las predicciones de los modelos econométricos (y, consecuentemente, disminuyeron notablemente la confianza en la efectividad de la aplicación de las políticas de estabilización), la investigación sobre la demanda de dinero fue estimulada nuevamente en conexión como el llamado "enfoque de cartera" sobre la balanza de pagos. En este sentido, la demanda de dinero y otros activos financieros juega un papel fundamental en la determinación de los movimientos de los tipos de cambio y la transmisión mundial de la inflación.

Al revisar los trabajos empíricos sobre el tema que se han hecho para México y para otros países en desarrollo, se tiene la impresión que los autores atribuyen a la estabilidad de la demanda de dinero una relevancia similar a la que puede tener en ciertos países industriales discutida anteriormente. Esta noción es, a mi modo de ver, incorrecta.

Por una parte, los países en desarrollo carecen generalmente de las instituciones financieras apropiadas para efectuar políticas monetarias de estabilización que dependen del grado de estabilidad de la demanda de dinero. Es difícil pensar que las autoridades monetarias de un país en desarrollo pudieran afectar la tasa de interés doméstica realizando, por ejemplo, operaciones de mercado abierto. Esto se debe, desde luego, a que la tasa de interés está (mas o menos) determinada en el exterior para la mayoría de estos países, y también a que carecen de un mercado de capitales importante. Así, el dilema clásico de si el Banco Central debe intervenir para controlar la masa monetaria o la tasa de interés no es un tema relevante para la mayoría de los países en desarrollo. 
Por otra parte, prácticamente ningún país no industrializado está en posibilidad de mantener un tipo de cambio flotante, de manera que la intervención del Banco Central en el mercado monetario con fines de regulación cambiaria de corto plazo es una opción no viable para estos países.

En el contexto de un país en desarrollo -y de México en particular-, la relevancia del comportamiento de la demanda de dinero está mas relacionada con aspectos dinámicos del ajuste de los mercados financieros que a consideraciones sobre la efectividad relativa de políticas alternativas. En la medida que se pueda identificar una relación estable, será posible estudiar con más cuidado la manera en que los mercados financieros se ajustan a perturbaciones de tipo externo. Así, por ejemplo, puede seguirse el efecto que tendría un incremento en la masa monetaria sobre los precios y/o la tenencia de otros activos financieros y no financieros, así como el impacto que tendría ésta en el mercado de bienes y servicios y en la balanza de pagos. Una relación estable permite, asimismo, realizar pronósticos que puedan ser útiles para fines de programación monetaria de corto plazo del sector público. Este último punto, sin embargo, está más asociado al comportamiento de la captación financiera global, de la cual el estudio de la demanda de dinero deben ser entendido sólo como una parte.

\subsection{Keynes y la Teoría Cuantitativa.}

Desde el punto vista teórico, los dos enfoques monetarios más importantes son, desde luego, la teoría cuantitativa del dinero y la teoría de Keynes, que han sido estudiados y desarrolladas extensamente.

En sus orígenes, la teoría cuantitativa del dinero fue más bien concebida como una teoría monetaria de los precios que como una teoría de la demanda de dinero. Esto es, la famosa identidad cuantitativa $\mathrm{MV}=\sum \mathrm{P}_{\mathrm{i}} \quad \mathrm{T}_{\mathrm{i}}$ se convierte en una ecuación de comportamiento cuando Fisher ofrece una hipótesis de la determinación de $\mathrm{V}$ y de $\mathrm{T}$ (que son independientes entre sí y también de M y de P), de manera que residualmente se obtiene una relación directa entre M y P. Posteriormente, Friedman (1956) desarrolla una teoría de demanda de dinero partiendo de un análisis microeconómico de maximización de utilidad, en el que trata al dinero como cualquier forma de activo en la que el individuo puede mantener su riqueza, Friedman llega a la siguiente formulación ${ }^{4}$ :

\footnotetext{
4/ Friedman (1956).
} 


$$
\mathrm{M}=\mathrm{L}\left(\mathrm{r}_{1}, \ldots, \mathrm{r}_{5} ; \mathrm{W} ; \mathrm{u}\right)
$$

donde $\mathrm{M}=$ cantidad demandada de dinero

$\mathrm{r}_{1}=$ rendimientos de los distintos activos (dinero, bonos, capital físico, capital humano y bienes durables)

$\mathrm{w}=$ riqueza total

$\mathrm{u}=$ otras variables (percepción de riesgos, etc...)

Si la demanda de dinero es homogénea de grado uno en precios e ingreso (y el rendimiento del dinero, $\mathrm{r}_{1}=\mathrm{P}$ ), la ecuación (1) se puede expresar:

$$
\frac{\mathrm{M}}{\mathrm{P}}=\mathrm{g}\left(\mathrm{r}_{2}, \ldots, \mathrm{r}_{5} ; \mathrm{Y} / \mathrm{P} ; \mathrm{u}\right)
$$

o bien

$$
\mathrm{Y}=\mathrm{v}\left(\mathrm{r}_{2}, \ldots, \mathrm{r}_{5} ; \mathrm{Y} / \mathrm{P} ; \mathrm{u}\right) \mathrm{M}
$$

Conviene notar que para llegar de la ecuación de demanda (1) a la forma usual de la teoría cuantitativa (1") es necesario postular la existencia de homogeneidad de grado uno con respecto a ingreso mencionada anteriormente.

Por otra parte, la idea central en la teoría monetaria de Keynes es la de un especulador que mantiene su riqueza en distintos activos, y que la transfiere continuamente de uno a otro buscando obtener el mayor rendimiento posible. El punto básico es el de una teoría de selección de activos; esto es, el de un enfoque de cartera. 
En la Teoría General, Keynes maneja un esquema simplificado que incluye sólo dos activos, dinero y bonos, ya que supone una relación de sustitución perfecta entre bonos y bienes de capital ${ }^{5 /}$. Siendo que el dinero es un activo líquido, por lo mismo una manera conveniente de mantener riqueza (debido a los famosos motivos transacción, precaución y especulación), el precio de los bonos (y por lo tanto de los bienes de capital) tiene que ser lo suficientemente atractivo como para que éstos sean incluidos en los portafolios de los inversionistas. Para Keynes, el punto más relevante es que las autoridades monetarias pueden cambiar la composición de la deuda gubernamental entre bonos y dinero, y por consiguiente alterar los precios relativos entre estos activos. Como los bonos y los bienes de capital tienen el mismo precio por definición, una reducción del precio de los bonos incentiva a los productores de bienes de capital a emplear una mayor cantidad de mano de obra.

En este modelo de sólo dos activos, la demanda de dinero se puede escribir:

$$
\mathrm{M}=\mathrm{L}(\mathrm{Y}, \mathrm{r}, \mathrm{P} \text {. }
$$

En este caso especial, la variable $r$ se interpreta como "la tasa de interés" que constituye el rendimiento común de bienes y dinero.

El punto importante de esta breve discusión, es que las formulaciones de Keynes y Friedman son similares desde el punto de vista teórico, ya que ambas corresponden a modelos de selección de activos. Friedman, toma en cuenta de manera explícita un portafolio mas completo en el que incluye la riqueza no humana, e introduce el concepto de ingreso permanente; sin embargo, las diferencias conceptuales se localizan mas precisamente en la volatilidad de la función. Keynes no suponía que las preferencias y expectativas de los inversionistas eran particularmente estables, por lo que sus prescripciones de política estaban mas asociadas al uso de instrumentos fiscales. Friedman, por el contrario, basado en una supuesta estabilidad de esta función, utiliza un modelo esencialmente keynesiano para llegar a conclusiones de política totalmente opuestas a las del mismo Keynes.

5/ En el Treatise, su concepción sobre el menú de activos disponible al inversionista era más amplia, y se enfocaba más directamente al problema de la determinación del precio de los bienes de capital. Este punto lo discuten ampliamente Leijonhufvud (1968), Hicks (1974) y Foley (1977). 
Las extensiones mas importantes derivadas del "motivo transacción" keynesiano son seguramente las realizadas por Baumol (1952) y Tobin $(1956)^{6 /}$. Bajo este punto de vista, el dinero se demanda por dos razones principales: falta de sincronización entre ingresos y pagos, y la existencia de costos de transacción. Este tipo de formulaciones relacionan la demanda de balances monetarios reales $\left(m^{d}\right)$ a "la tasa de interés" $r$ pagada sobre activos que pueden ser sustitutos cercanos del dinero, y a una medida de la actividad económica ( o del número de transacciones realizadas, que usualmente es el producto nacional bruto.

La versión más sencilla de la fórmula Baumol Tobin es la famosa "ley de la raíz cuadrada",

$$
\mathrm{M}^{\mathrm{d}}=\mathrm{k} \mathrm{y}^{1 / 2} \mathrm{r}^{1 / 2}
$$

en la que $\mathrm{k}$ representa el costo de transacción en el que se incurre al pasar de dinero a otros activos menos líquidos y viceversa. Esta fórmula implica una elasticidad ingreso de .5 y elasticidad de -.5 con respecto a la tasa de interés. Distintas versiones de la ecuación (3) han sido estimadas extensamente utilizando datos anuales (para E.U.), encontrándose elasticidades precio (de largo plazo) entre 0 y -.5, y elasticidades ingreso entre .5 y la unidad, sugiriendo la existencia de economías de escala en el uso del dinero para transacciones ${ }^{\underline{7}}$.

Hasta la fecha, sin embargo, no han surgido enfoques teóricos que integren consideraciones de tipo especulativo (o de portafolio) y de transacciones en un modelo bien fundamentado desde el punto de vista microeconómico.

\subsection{Formulaciones Empíricas.}

De la sección anterior resulta claro que los distintos enfoques teóricos sobre demanda de dinero sugieren formas funcionales de estimación empírica que incluyen esencialmente las mismas variables $(\mathrm{m}=\mathrm{M} / \mathrm{P}, \mathrm{y}=\mathrm{Y} / \mathrm{P})$ :

$$
m^{d}=f\left(y^{i}, r\right)
$$

\footnotetext{
6) Para una generalización del trabajo de Tobin y Baumol, véase a Barro (1976).

7/ Véase, p. Ejemplo, los estudios de Meltzer (1963) y Laidler (1966).
} 
La variable y puede tratarse de ingreso corriente $\left(\mathrm{y}^{\mathrm{c}}\right)$ si se sigue el enfoque de transacciones, o del ingreso permanente $\left(\mathrm{y}^{\mathrm{p}}\right)$ como una variable sucedánea de la riqueza en el caso que se adopte un modelo de portafolio. A su vez, la variable $r$ que representa el costo de oportunidad de mantener dinero, puede consistir en un promedio ponderado de tasas de interés, en alguna tasa específica, o bien en un vector de rendimientos sobre distintos activos tanto financieros como no financieros, dependiendo del modelo que se adopte.

La formulación más simple y usual de la ecuación ( 4 ) es

$$
m^{d}=a_{0}+a_{1} y_{t}+a_{2} r_{2}+\varepsilon_{t}
$$

donde $\varepsilon_{\mathrm{t}}$ es un término de error aleatorio. Cuando se utilizan datos trimestrales es común suponer que el mercado monetario se encuentra en desequilibrio en el corto plazo, y que el público se ajusta gradualmente a sus saldos deseados $\left(\mathrm{m}^{*}\right)$ :

$$
\begin{aligned}
& \mathrm{m}^{*}=\mathrm{a}_{0}+\mathrm{a}_{1} \mathrm{y}_{\mathrm{t}}+\mathrm{a}_{2} \mathrm{r}_{2}+\varepsilon_{\mathrm{t}} \\
& \mathrm{m}_{\mathrm{t}}-\mathrm{m}_{\mathrm{t}-1}=\lambda\left(\mathrm{m}_{\mathrm{t}}^{*}-\mathrm{m}_{\mathrm{t}-1}\right) .
\end{aligned}
$$

La ecuación ( 7 ) representa dicho proceso de ajuste. Combinando ( 6 ) y ( 7 ) obtenemos

$$
\mathrm{m}_{\mathrm{t}}=\alpha_{0}+\alpha_{1} \mathrm{y}_{\mathrm{t}}+\alpha_{2} \mathrm{r}_{2}+\alpha 3 \mathrm{~m}_{\mathrm{t}-1}+\lambda \varepsilon_{\mathrm{t}}
$$

donde $\alpha_{0}=\lambda \mathrm{a}_{0}, \alpha_{1}=\lambda \mathrm{a}_{1}+\alpha_{2}=\lambda \mathrm{a}_{2}+\alpha_{3}=1-\lambda$. Dados los supuestos normales sobre la distribución de $\varepsilon_{\mathrm{t}}$, la ecuación ( 8 ) puede estimarse directamente por mínimos cuadrados ordinarios, $\mathrm{y}$ los $\hat{\alpha}_{\mathrm{i}}$ tendrán las propiedades usuales. Nótese que esta ecuación se deriva del "enfoque transacciones" debido a que tanto $r_{t}$ como $y_{t}$ son variables corrientes (observadas). 
Otra forma usual de estimar la ecuación ( 4 ) consiste en incluir el ingreso permanente (y/o la tasa de interés esperada) en vez del ingreso corriente, y suponer que el ingreso permanente puede aproximarse mediante un proceso de expectativas adaptativas ${ }^{8 /}$ :

$$
\begin{aligned}
& \mathrm{m}_{\mathrm{t}}^{*}=\mathrm{b}_{0}+\mathrm{b}_{1} \mathrm{y}_{\mathrm{t}}^{\mathrm{p}}+\mathrm{b}_{2} \mathrm{r}_{2}+\varepsilon_{\mathrm{t}} \\
& \mathrm{y}_{\mathrm{t}}^{\mathrm{p}}-\mathrm{y}_{\mathrm{t}-1}^{\mathrm{p}}=\gamma\left(\mathrm{y}_{\mathrm{t}}-\mathrm{y}_{\mathrm{t}-1}^{\mathrm{p}}\right)
\end{aligned}
$$

De nuevo, combinando ( 7 ), ( 9 ) y (10) se obtiene:

$\mathrm{m}_{\mathrm{t}}=\beta_{0}+\beta_{1} \mathrm{y}_{\mathrm{t}}+\beta_{2} \mathrm{r}_{\mathrm{t}}+\beta_{3} \mathrm{r}_{\mathrm{t}-1}+\beta_{4} \mathrm{~m}_{\mathrm{t}-1}+\beta_{5} \mathrm{~m}_{\mathrm{t}-2}+\mathrm{u}_{\mathrm{t}}$

Las $\beta_{1}$ son funciones no lineales de los parámetros originales, por lo que no pueden obtenerse estimaciones simples de estos parámetros.

$$
\mathrm{u}_{\mathrm{t}}=\varepsilon_{\mathrm{t}}-(1-\gamma) \varepsilon_{\mathrm{t}-1}
$$

Esta situación plantea un problema serio de estimación ya que $\mathrm{m}_{\mathrm{t}-1}$ está obviamente correlacionado con $\varepsilon_{\mathrm{t}-1} \mathrm{y}$ por lo tanto con $\mathrm{u}_{\mathrm{t}}$, de manera que los estimadores $\hat{\beta}_{1}$ obtenidos por el método de mínimos cuadrados ordinarios (MCO) serán sesgados e inconsistentes. Adicionalmente, la ecuación tendrá problemas de correlación seriada (según se aprecia en la expresión del error) y de multicolinealidad, debido a la inclusión de dos rezagos de la variable dependiente ${ }^{9}$. Si se añade una segunda hipótesis de expectativas adaptativas con respecto a la tasa de interés, se obtendrá una expresión parecida a la ecuación (11) con una estructura de errores aún más complicada ${ }^{10 /}$.

Un problema adicional de especificación que se puede encontrar al estimar cualquier forma de la ecuación ( 4 ) es el de simultaneidad. Es claro que al estimar una función de demanda de dinero se está haciendo un supuesto implícito sobre el mecanismo de ajuste en el mercado monetario; esto es,

\footnotetext{
8/ La ecuación (10) implica que $\mathrm{y}^{\mathrm{p}}$ es un simple rezago distribuido de $\mathrm{y}^{\mathrm{t}}$ de tipo Koyck.

9/ Véase a Johnston (1972), Cap. 10
} 
que la oferta se ajuste en el mercado monetario; esto es, que la oferta se ajusta en forma pasiva a cambios en la demanda. Este punto es importante porque los datos que se utilizan en cualquier formulación empírica corresponden a la oferta, de manera que si los argumentos incluidos en la función de demanda (la tasa de interés y el ingreso) se modifican al variar la oferta, los coeficientes estimados por MCO serán sesgados e inconsistentes.

\section{La Demanda de Dinero en México: Estudios Empíricos.}

Los estudios empíricos sobre demanda de dinero para México que se han producido hasta la fecha son los de A. Montemayor (1967), J.L. Genel (1971), J. Cambiaso (1979), L. Ramírez (1977), A.

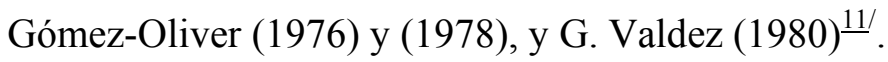

Aurelio Montemayor utilizó datos anuales y trimestrales de 1940 a 1963, excluyendo parte del período correspondiente a la Segunda Guerra Mundial (los años 1943-1947), en un modelo de ajuste parcial en el que incluyó como variables independientes el ingreso y la inflación esperados; las series fueron construidas utilizando el proceso de expectativas adaptativas descrito en la sección anterior. En resumen, Montemayor obtuvo elasticidades ingreso de largo plazo del orden de .7, aunque sus coeficientes de inflación esperada no resultaron significativos.

Genel, por su parte, sí incluye la tasa de interés en sus regresiones, aunque esta variable no le resulta significativamente en ningún caso debido probablemente a errores de especificación que resultan difíciles de detectar debido a que el autor no reporta el estadístico Durbin-h. Este autor utiliza datos anuales de 1950 a 1969, y estima ecuaciones tanto de corto como de largo plazo. Algunos de sus resultados se presentan en el Cuadro 1.

En sus dos trabajos publicados sobre el tema (1976) y (1978), Gómez Oliver utiliza esencialmente el mismo modelo y la misma base de datos. El modelo planteado es uno de ajuste parcial y expectativas adaptativas para el ingreso permanente y la inflación esperada.

10/ Feige (1967) estimó una ecuación parecida a (11), y logró identificar los parámetros originales del modelo mediante un método no lineal restringido, de dos etapas inspirado en un artículo de Zellner, Huang y Chaw (1965). Véase también el artículo de Goldfeld (1973).

11. Estos son los trabajos que se lograron identificar. Recientemente la Subdirección de Investigación Económica del Banco de México (1979) compiló una bibliografía extensa de trabajos con el sector financiero mexicano. 


$$
\begin{gathered}
\mathrm{m}_{\mathrm{t}=}=\mathrm{a}_{0}+\mathrm{a}_{1} \mathrm{y}_{\mathrm{t}}^{*}+\mathrm{a}_{2} \pi_{\mathrm{t}}^{*}+\mathrm{a}_{3} \mathrm{~m}_{\mathrm{t}-1}+\varepsilon_{\mathrm{t}} \\
\mathrm{y}_{\mathrm{t}}^{*}=\lambda_{1} \mathrm{y}_{\mathrm{t}}+\left(1-\lambda_{1}\right) \mathrm{y}_{\mathrm{t}-1}^{*} \\
\pi_{\mathrm{t}}^{*}=\lambda_{1} \pi_{\mathrm{t}}+\left(1-\lambda_{2}\right) \pi_{\mathrm{t}-1}^{*}
\end{gathered}
$$

Gómez Oliver, sin embargo, no estima este modelo, sino que obtiene valores para $\pi_{\mathrm{t}}^{*} \mathrm{y}_{\mathrm{t}}^{*} \mathrm{de}$ promedios ponderados de valores del período corriente y del período anterior ${ }^{12 /}$ :

$$
\begin{aligned}
& \mathrm{y}_{\mathrm{t}}^{*}=\lambda_{1} \mathrm{y}_{\mathrm{t}}+\left(1-\lambda_{1}\right) \mathrm{y}_{\mathrm{t}-1} \\
& \pi_{\mathrm{t}}^{*}=\lambda_{1} \pi_{\mathrm{t}}+\left(1-\lambda_{2}\right) \pi_{\mathrm{t}-1}
\end{aligned}
$$

evitando así los problemas de correlación entre las variables dependientes rezagadas y el término del error. En su primer trabajo, este autor estima la ecuación (12) obteniendo en general buenos resultados los que, sin embargo, deben interpretarse con cierta reserva debido a que no se publicó la estadística relevante para medir el grado de correlación seriada, que usualmente está presente en este tipo de estimaciones.

En su segundo trabajo, Gómez Oliver estima la siguiente ecuación:

$$
\mathrm{Mt}=\mathrm{a} 0 \mathrm{y}_{\mathrm{t}}^{*}+\mathrm{a}_{2} \pi_{\mathrm{t}}^{*}+\mathrm{a} 4\left(\dot{\mathrm{M}}_{\mathrm{t}}-\dot{\mathrm{M}}_{\mathrm{t}}^{*}\right)+\varepsilon_{\mathrm{t}}
$$

12/ Sustituyendo las expresiones para $y_{t}^{*} y \pi_{t}^{*}$ en (12) se obtiene:

$$
\mathrm{m}_{\mathrm{t}}=\alpha_{0}+\alpha_{1} \mathrm{y}_{\mathrm{t}}+\alpha_{2} \mathrm{yt}_{\mathrm{t}}+\alpha_{3} \pi_{\mathrm{t}}+\alpha_{4} \pi_{\mathrm{t}-1}
$$

$$
+\alpha_{5} \mathrm{~m}_{\mathrm{t}-1}+\alpha_{6} \mathrm{~m}_{\mathrm{t}-2}+\alpha \mathrm{m}_{\mathrm{t}-3}+\mathrm{u}_{\mathrm{t}}
$$

donde ut $=\varepsilon_{\mathrm{t}}+\left(2-\lambda_{1}-\lambda_{2}\right) \varepsilon_{\mathrm{t}-1}+\left(1-\lambda_{1}\right)\left(1-\lambda_{2}\right) \varepsilon_{\mathrm{t}-2}$

Esta ecuación es la que se deriva realmente del modelo planteado. En la ecuación (12) está estimada en forma semilogarítmica (en m e y) per capita. 
donde el término $\left(\dot{\mathrm{M}}_{\mathrm{t}}-\dot{\mathrm{M}}_{\mathrm{t}}\right.$ ) intenta captar el efecto sobre los saldos reales que tienen los movimientos no anticipados de la oferta nominal de dinero. Aunque el autor no menciona de manera explícita el cálculo de $\dot{\mathrm{M}}_{\mathrm{t}}$, lo más probable es que esta variable sea una promedio ponderado de observaciones de dos períodos, en cuyo caso el término del error en (13) tendrá problemas adicionales de autocorrelación. De hecho, el estadístico Durbin-h indica la presencia de autocorrelación en la ecuación reportada para $\mathrm{M}_{1}$ que incluye dicho término, por lo que sus estimadores son ineficientes e inconsistentes. En el resto de sus estimaciones, sin embargo, obtiene resultados aceptables por lo que concluye que “... la demanda de dinero real, en México, puede considerarse una función muy estable de variables económicas" prueba de estabilidad.

A su vez, J. Cambiaso efectuó una estimación de demanda de dinero para varios países latinoamericanos entre los que figura México. Utiliza un modelo similar al de Gómez Oliver, y una base de datos anual de 1954 a 1973. Encontró que, en el caso de México, la inflación no influyó de manera significativa en la demanda de dinero y que, en general, la definición más amplia de dinero es la que mejor funciona. De nuevo, aunque el autor no reporta el estadístico apropiado en algunas de sus estimaciones, es muy probable que éstas tengan también problemas de correlación seriada ${ }^{14}$.

El estudio de Luis Ramírez aplica básicamente las mismas ecuaciones de Gómez Oliver para examinar el comportamiento de la demanda de dinero de 1947 a 1957 a nivel trimestral. A la ecuación (13), el autor añade una variable de expectativas de devaluación para capturar la influencia de éstas en el comportamiento de la función de demanda. Dicha variable la define simplemente como la diferencia entre el crecimiento esperado de los precios en México y E.U., calculado también mediante el método de expectativas adaptativas. Debido a la poca variación del índice de precios al mayoreo en E.U. durante el período, es claro que existe un muy alto grado de multicolinealidad entre las variables que mide las expectativas de inflación y las de devaluación, por lo que el autor opta por hacer estimaciones separadas, concluyendo que las expectativas de devaluación pueden ser aproximadas por las correspondientes a la inflación esperada.

(1968), p. 21

14/ El estadístico apropiado para medir la existencia de correlación seriada de primer orden en presencia de una variable dependiente rezagada es el Durbin-h. Cambiaso reporta el Durbin-Watson. 
El problema es, desde luego, que la especificación de la variable de expectativas de devaluación no es interesante precisamente porque se está midiendo casi exclusivamente la inflación en México.

En un trabajo muy reciente, G. Valdez estima una ecuación convencional de demanda de dinero basada en un modelo de ajuste parcial que incluye las variables ingreso permanente e inflación esperada. En una primera etapa, este autor deriva series de estas dos variables consistentes con el enfoque de expectativas racionales, utilizando métodos avanzados de teoría del control que se han ensayado recientemente por Sargent (1979). Posteriormente, utiliza las series generadas para estimar una ecuación de demanda simple por mínimos cuadrados ordinarios y realiza pruebas de autocorrelación de residuales por el método de Box-Jenkins. Basado en estas pruebas, el autor efectúa una estimación conjunta de los coeficientes de la regresión y del proceso Box-Jenkins ${ }^{15}$.

Aunque la aplicación de métodos econométricos novedosos a estimación de este tipo de funciones es muy interesante, queda pendiente el problema de la identificación de las causas económicas que motivan en primer lugar el estudio en cuestión. Esto es, el procedimiento empleado corresponde a una especie de "caja negra" en la que no se puede precisar lo que en realidad está ocurriendo. Sus resultados principales se resumen en el siguiente cuadro.

15/ El modelo Box-Jenkins estimado fue un ARIMA $(4,0,1)$. 
CUADRO 1

CUADRO COMPARATIVO DE LOS ESTUDIOS DE DEMANDA DE DINERO PARA MEXICO

\begin{tabular}{|c|c|c|c|c|c|c|}
\hline $\begin{array}{c}\text { Definición } \\
\text { de } \\
\text { Dinero }\end{array}$ & Autor & $\begin{array}{c}\text { Período } \\
\text { y } \\
\text { Frecuencia }\end{array}$ & $\begin{array}{c}\text { Elasticidad } \\
\text { ingreso } \\
\text { Corto } \\
\text { Plazo } \\
\end{array}$ & $\begin{array}{c}\text { Elasticidad } \\
\text { ingreso } \\
\text { Largo } \\
\text { Plazo } \\
\end{array}$ & $\begin{array}{l}\text { Elasticidad } \\
\text { costo de } \\
\text { operación }\end{array}$ & $\begin{array}{l}\text { Velocidad } \\
\text { de ajuste }\end{array}$ \\
\hline \multirow[t]{12}{*}{$\mathrm{M}_{1}$} & A. Montemayor & $1940-1942$ & & & & \\
\hline & & $\begin{array}{l}1948-1963 \\
\text { anual }\end{array}$ & .476 & .823 & & .578 \\
\hline & Gómez Oliver & $1934-1940$ & & & & \\
\hline & & $\begin{array}{l}1948-1973 \\
\text { anual }\end{array}$ & .487 & .285 & -1.260 & 0.511 \\
\hline & J.L. Genel & $\begin{array}{l}1950-1969 \\
\text { anual }\end{array}$ & .486 & 1.200 & & 0.415 \\
\hline & J. Cambiaso & $1954-1973$ & & & & \\
\hline & & anual & .877 & 2.203 & -0.501 & 0.602 \\
\hline & A. Montemayor & $1940-1942$ & & & & \\
\hline & & $\begin{array}{l}1948-1963 \\
\text { trimestral }\end{array}$ & .285 & .717 & & 0.398 \\
\hline & L. Ramírez & 1947II-1957IV & & & & \\
\hline & & trimestral & .518 & 1.385 & -0.010 & 0.626 \\
\hline & G. Valdez & $\begin{array}{l}\text { 1958III-1979III } \\
\text { trimestral }\end{array}$ & .245 & 1.065 & -0.080 & 0.230 \\
\hline \multirow[t]{11}{*}{$\mathrm{M}_{2}$} & A. Montemayor & $1940-1942$ & & & & \\
\hline & & $\begin{array}{l}1948-1963 \\
\text { anual }\end{array}$ & 142 & 1.421 & & 0.100 \\
\hline & Gómez Oliver & $1934-1940$ & & & & \\
\hline & & $\begin{array}{l}1948-1963 \\
\text { anual }\end{array}$ & .595 & 1.061 & -1.950 & 0.561 \\
\hline & J. Cambiaso & $1954-1973$ & & & & \\
\hline & & anual & .793 & 1.504 & -0.717 & 0.473 \\
\hline & A. Montemayor & 1940-1942 & & & & \\
\hline & & $\begin{array}{l}1948-1963 \\
\text { trimestral }\end{array}$ & .122 & .729 & & 0.167 \\
\hline & L. Ramírez & 1947II-1957IV & & & & \\
\hline & & trimestral & .491 & 1.158 & -0.010 & 0.576 \\
\hline & G. Valdez & $\begin{array}{l}\text { 1959III-1979III } \\
\text { trimestral }\end{array}$ & 255 & 1.121 & -093 & 0229 \\
\hline
\end{tabular}




\section{Estimaciones: Primeros Resultados.}

Al revisar la literatura empírica sobre demanda de dinero, llama la atención la gran cantidad de aspectos que continúan debatiéndose, y que corresponden a otras tantas especificaciones de la función a estimar. Por otra parte, de la sección anterior se desprende que la investigación empírica existente sobre México es aun muy reducida, que sólo se han estudiado unos cuantos puntos relevantes, y que los resultados obtenidos no son del todo sólidos, aunque, desde luego, representan un punto de partida importante.

En este trabajo se tratarán sólo cuatro aspectos sobre la demanda de dinero en México: la relevancia de incluir las tasas de interés pasivas como variables explicativas; el problema del ajuste a los saldos deseados; la definición más estable de dinero; y la comparación de algunas especificaciones alterativas de la función.

\subsection{Tasas de Interés e Inflación.}

Como se apuntó en la sección anterior, los autores que han realizado investigaciones empíricas sobre demanda de dinero para México, han utilizado la inflación esperada para medir el costo de oportunidad de mantener saldos monetarios, descartando el uso de la tasa de interés.

A. Montemayor reporta que utilizó esta variable en sus estimaciones anuales y trimestrales, con resultados poco satisfactorios, por lo que concluye que no es relevante para el caso de México. Gómez-Oliver, por su parte, argumenta que el uso de la tasa de interés no es apropiado para medir el costo de oportunidad de mantener saldos monetarios (en México) debido a que esta tasa está fijada por el Banco de México, y constituye una variable de política económica. Este último argumento parece sin embargo, poco convincente.

En primer término, aunque es cierto que el Banco de México fija las tasas de interés pasivas, es obvio que éstas no son independientes de "la tasa de interés" internacional debido a que existe libre convetibilidad del peso. Por otra parte, aun en el caso en que el Banco Central pudiese fijar efectivamente las tasas de interés con independencia de lo que sucede en el exterior, éstas constituirían, de todas maneras, el costo de oportunidad de mantener saldos monetarios. El concepto de costo de 
oportunidad no implica que la variable utilizada para medirlo tenga que ser determinada libremente por el mercado.

A su vez, R. Montemayor concluye que la tasa de interés no es una variable importante para explicar la demanda de dinero en México, debido a que esta variable no equilibra al mercado monetario, ya que tampoco tuvo éxito en algunos intentos que realizó. De nuevo, aunque la tasa de interés no se mueva para acomodar los desequilibrios en el mercado monetario, y el proceso de ajuste sea vía balanza de pagos o mercado de bienes y servicios, la tasa de interés sigue siendo una variable relevante que mide el costo de mantener dinero ${ }^{16 /}$

En consecuencia, dada la importancia teórica de las tasas de interés en la demanda de dinero, parece importante explorar con más cuidado su relevancia empírica en el caso de México.

Como un primer paso, se plantea el siguiente modelo correspondiente al "enfoque transacciones" discutido anteriormente:

$$
\begin{gathered}
\ln \mathrm{m}^{*}=\mathrm{a}_{0}+\mathrm{a}_{1} \ln \mathrm{y}_{\mathrm{t}}^{\mathrm{c}}+\mathrm{a}_{2} \ln \mathrm{r}_{\mathrm{i}}^{\mathrm{c}}+\mathrm{a}_{3} \ln \left(\frac{\mathrm{P}_{\mathrm{t}}}{\mathrm{P}_{\mathrm{t}-1}}\right)+\varepsilon_{\mathrm{t}} \\
\mathrm{m}_{\mathrm{t}}-\mathrm{m}_{\mathrm{t}-1}=\lambda\left(\mathrm{m}^{*}-\mathrm{m}_{\mathrm{t}-1}\right)
\end{gathered}
$$

que resulta en la ecuación

$$
\begin{aligned}
& \ln \mathrm{m}_{\mathrm{t}}=\alpha_{0}+\alpha_{1} \ln \mathrm{y}_{\mathrm{t}}^{\mathrm{c}}+\alpha_{2} \ln \mathrm{r}_{\mathrm{i}}^{\mathrm{c}}+\alpha_{3} \ln \pi_{\mathrm{t}}+\alpha_{4} \ln \mathrm{m}_{\mathrm{t}-1} \\
& +\mathrm{d}_{1}+\mathrm{d}_{2}+\mathrm{d}_{3}+\lambda \varepsilon_{\mathrm{t}}
\end{aligned}
$$

donde $d_{1}, d_{2} y_{3}$ corresponden a variables ficticias utilizadas para captar la estacionalidad de la serie de dinero ${ }^{17 /}$. La ecuación (14) contiene asimismo un término de expectativas inflacionarias $\left(\pi_{\mathrm{t}}\right)$ que, al

17. Las variables ficticias resultaron altamente significativas en todas las ecuaciones estimadas, aunque no se reportan en los cuadros correspondientes por razones de espacio. 
igual que la tasa de interés, representa un costo de oportunidad ${ }^{181}$. Como una primera aproximación, se tomó la inflación corriente.

Una dificultad con la que seguramente han tropezado los autores que se han ocupado de estudios de la demanda de dinero en México, es la disponibilidad de información sobre tasa de interés, ya que sólo en fechas relativamente recientes se han publicado series consistentes con periodicidad mensual. Para efectuar las estimaciones presentadas en este trabajo se elaboraron tres series de tasas de interés:

$\mathrm{RT}=$ tasa pasiva pagada sobre instrumentos no monetarios. Serie ponderada.

$\mathrm{RL}=$ tasa pasiva pagada sobre instrumentos líquidos ofrecidos al público (a plazo menor a un mes).

$\mathrm{RNL}=$ tasa pasiva pagada sobre instrumentos no líquidos (a plazo mayor a un mes).

La serie trimestral de ingreso se obtuvo a partir del índice de producción industrial y de la cifra de PIB anual, y la de precios utilizando el índice de precios al consumidor y el deflactor implícito del PIB. El agregado $\mathrm{m}_{\mathrm{t}}$ corresponde a la definición de dinero $\mathrm{M}_{1}=$ billetes $\mathrm{y}$ monedas + cuentas de cheques $^{\underline{19} /}$.

La ecuación (14) se estimó con datos trimestrales para tres períodos: 1960( I ) a 1972 (IV); 1960( I ) a 1976 (III); y 1960 ( I ) a 1979 (IV), considerando que el primer período fue de estabilidad de precios e ingreso, mientras que el segundo incluye el período inflacionario predevaluación, y el tercero capta los efectos post-devaluatorios. Se estimaron varias versiones de la ecuación (14) utilizando el método de Cochrane-Orcutt para corregir la presencia de correlación seriada en el error; las estimaciones se presentan en los cuadros 2 y 3 .

18/ $\pi_{\mathrm{t}}=\left(\frac{\mathrm{P}_{\mathrm{t}}}{\mathrm{P}_{\mathrm{t}-1}}\right) ; \ln \pi_{\mathrm{t}}=\ln \left(1+\frac{\Delta \mathrm{P}_{\mathrm{t}}}{\mathrm{P}_{\mathrm{t}-1}}\right)=\frac{\Delta \mathrm{P}_{\mathrm{t}}}{\mathrm{P}_{\mathrm{t}-1}}$

19/ En el Apéndice Estadístico se detallan con precisión los instrumentos incluidos en cada serie de tasas de interés, así como la metodología utilizada para construir las series trimestrales de ingreso y de precios. $\mathrm{m}_{\mathrm{t}} \mathrm{y} \mathrm{y}_{\mathrm{t}}^{\mathrm{c}}$ están deflacionadas por el índice de precios al consumidor. 
Las ecuaciones estimadas arrojan resultados interesantes y consistentes con los que se podría esperar a priori, aunque bastante diferentes a los reportados en los trabajos discutidos en la sección anterior.

En el período de relativa estabilidad de precios e ingresos (1960-72), los coeficientes de la variable "inflación" no son significativos para ninguna de las ecuaciones estimadas, a diferencia de los coeficientes correspondientes a las distintas tasas de interés que sí son significativos. Al estimar la primera ecuación para este período (2.1) incluyendo la tasa de líquidos, la de no líquidos y la de inflación, ninguno de los coeficientes correspondientes es significativo, lo que se explica por la existencia de multicolinealidad de los distintos rendimientos como se aprecia en la Gráfica 1. Al realizar estimaciones utilizando las distintas tasas separadamente se obtienen, sin embargo, mejores resultados, debido también a que a partir de 1973 las tasas de rendimientos líquidos y no líquidos se mueven de manera distinta.

Comparando las distintas tasas utilizadas en las estimaciones del Cuadro 2, la tasa de líquidos aparece como la más robusta ya que es significativa en los tres períodos considerados. Sin embargo, al utilizar las tasas totales y la de no líquidos se observa que la velocidad de ajuste (1-coeficiente de mt-1) es mayor, y más congruente con los resultados observados en otros países ${ }^{\underline{20}}$. Eliminado la inflación, en el Cuadro 3, también se aprecia el mismo comportamiento.

20/ Véase, por ejemplo, el estudio de T. Baliño (1977) y J. Báez (1979) para la Argentina. 
Gráfica 1

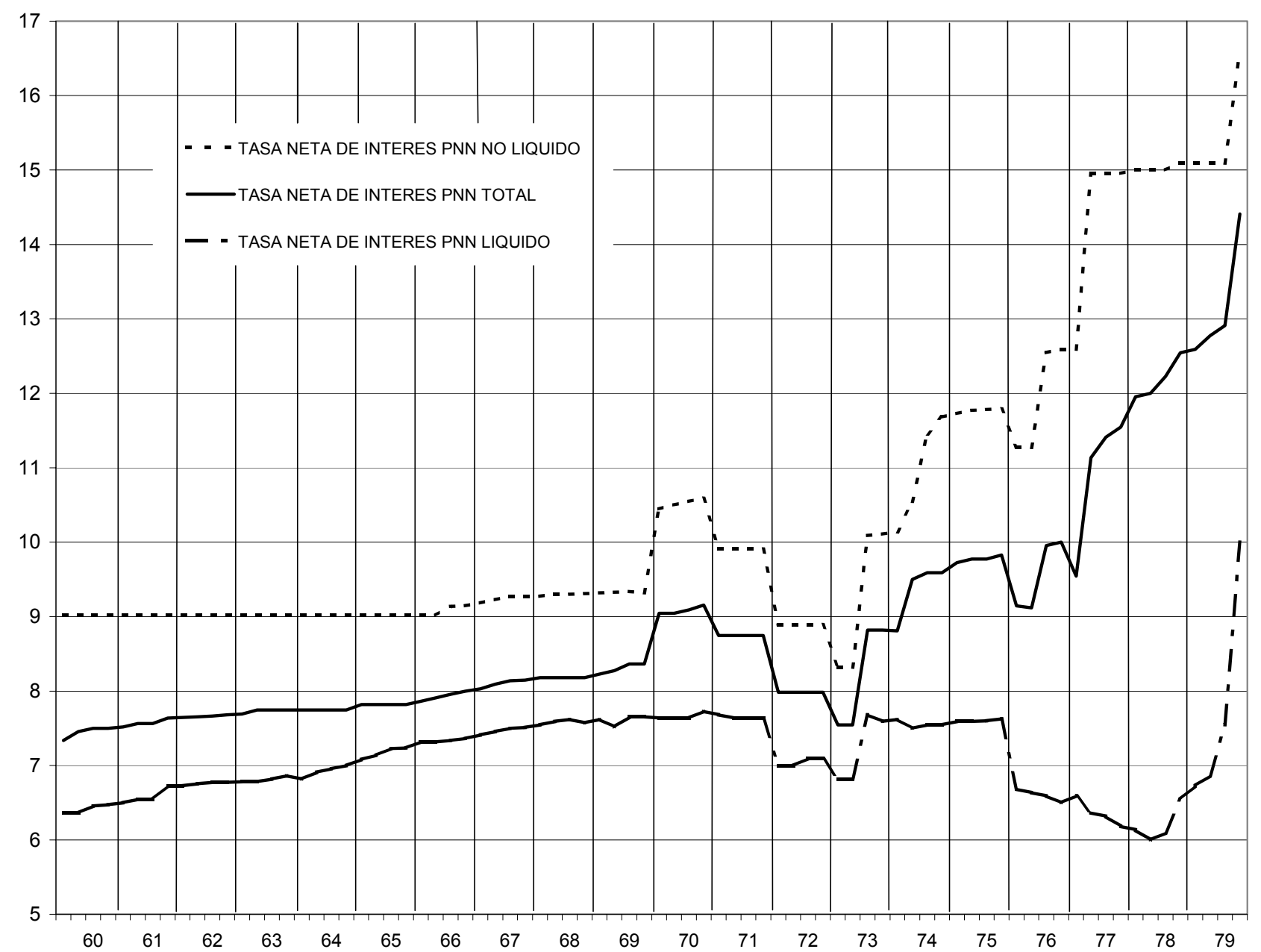


CUADRO 2

Estimación de la Ecuación (14)

(ajuste real)

Variable Dependiente $\mathrm{M}_{1} / \mathrm{P}$

\begin{tabular}{|c|c|c|c|c|c|c|c|c|c|c|c|c|}
\hline Ecuación & Período & $\mathrm{V}_{+}^{\mathrm{C}}$ & $\mathrm{RT}_{\mathrm{t}}$ & $\mathrm{RL}_{\mathrm{t}}$ & $\mathrm{RNL}_{\mathrm{t}}$ & $\pi_{\mathrm{t}}$ & $\mathrm{m}_{\mathrm{t}-1}$ & $\mathrm{R}_{2}$ & Durbin-h & $\mathrm{F}(.,)$. & $\mathrm{R}_{\mathrm{o}}$ & Error \\
\hline 2.1 & $(1960-1972)$ & $.226^{*}$ & & -.092 & -.105 & -.192 & $-.810 *$ & .994 & .090 & $(8,41)$ & -.28 & .0223 \\
\hline 2.2 & (1960-1976 III) & $\begin{array}{l}(2.19) \\
.116^{*} \\
(1.97)\end{array}$ & & $\begin{array}{l}(-.72) \\
-.066^{*} \\
(-1.77)\end{array}$ & $\begin{array}{l}(-1.33) \\
-.066^{*} \\
(-1.77)\end{array}$ & $\begin{array}{c}(-.59) \\
-.086^{*} \\
(-1.77)\end{array}$ & $\begin{array}{c}(7.33) \\
.921 * \\
(11.88)\end{array}$ & .995 & .886 & $\begin{array}{c}784.1 \\
(8,56) \\
1584.2\end{array}$ & -.48 & .0243 \\
\hline 2.3 & $(1960-1979)$ & .052 & & .014 & -.014 & $-.210 *$ & $.980^{*}$ & .995 & .655 & $(8,69)$ & -.36 & .0282 \\
\hline 2.4 & $(1960-1972)$ & $\begin{array}{l}(.64) \\
.259 * \\
(2.53)\end{array}$ & $\begin{array}{l}-.175^{*} \\
(-2.21)\end{array}$ & $(.52)$ & $(052)$ & $\begin{array}{c}(-3.73) \\
-.087 \\
(-.35)\end{array}$ & $\begin{array}{c}(12.33) \\
.776^{*} \\
(7.72)\end{array}$ & .993 & 1.000 & $\begin{array}{c}1624.9 \\
(7,42) \\
902.8\end{array}$ & -.27 & .0224 \\
\hline 2.5 & (1960-1976 III) & .151 & $-.134 *$ & & & -.043 & $.883 *$ & .995 & .722 & $(7,57)$ & -.44 & .0232 \\
\hline 2.6 & (1960-1979) & $\begin{array}{c}(1.81) \\
.103 \\
(128)\end{array}$ & $\begin{array}{c}(-2.43) \\
.041 \\
(123)\end{array}$ & & & $\begin{array}{l}(-.68) \\
-.158 * \\
(-3.13)\end{array}$ & $\begin{array}{c}(11.07) \\
.910 * \\
(-1.62)\end{array}$ & .994 & .484 & $\begin{array}{c}1741.1 \\
(7,70) \\
1802.0\end{array}$ & -.25 & .0281 \\
\hline 2.7 & $(1960-1972)$ & $.197^{*}$ & & $-.199 *$ & & -.385 & $.831^{*}$ & .993 & 1.100 & $(7,42)$ & -.25 & .0227 \\
\hline 2.8 & (1960-1976 III) & $\begin{array}{c}.059 \\
.05911\end{array}$ & & $-.118 *$ & & $-1.155^{*}$ & $.971^{*}$ & .995 & .785 & (7,57) & -.45 & .0231 \\
\hline 2.9 & $(1960-1979)$ & $\begin{array}{c}(.822) \\
.072\end{array}$ & & $\begin{array}{l}(-2.50) \\
-.88 *\end{array}$ & & $\begin{array}{l}(-2.78) \\
-.197 *\end{array}$ & $\begin{array}{c}(13.34) \\
.964 *\end{array}$ & .995 & .565 & $\begin{array}{c}1746.3 \\
(7,70)\end{array}$ & -.36 & .0275 \\
\hline 2.10 & $(1960-1972)$ & $\begin{array}{l}(1.03) \\
.243^{*} \\
(019)\end{array}$ & & $(-2.34)$ & $-.140 *$ & $\begin{array}{c}(-3.94) \\
-.036\end{array}$ & $\begin{array}{c}(13.17) \\
.777 *\end{array}$ & .993 & 1.000 & $\begin{array}{c}1876.4 \\
(7,42)\end{array}$ & -.28 & .0223 \\
\hline 2.11 & (1960-1976 III) & $\begin{array}{l}(2.19) \\
.129\end{array}$ & & & $\begin{array}{l}(-2.27) \\
-.077 *\end{array}$ & $\begin{array}{l}(-.15) \\
-.041\end{array}$ & $\begin{array}{l}(7.77) \\
.893 *\end{array}$ & .995 & .983 & $\begin{array}{r}906.5 \\
(7,57)\end{array}$ & -.42 & .0236 \\
\hline 2.12 & (1960-1979) & $\begin{array}{c}(1.55) \\
.108 \\
(1.29)\end{array}$ & & & $\begin{array}{c}(-1.93) \\
-.028 \\
(.96)\end{array}$ & $\begin{array}{l}(-.60) \\
-.16^{*} \\
(-2.88)\end{array}$ & $\begin{array}{c}(10.9) \\
.909 * \\
(11.07)\end{array}$ & .994 & .655 & $\begin{array}{c}1683.7 \\
(7,70) \\
1787.4\end{array}$ & -.25 & .0282 \\
\hline 2.13 & $(1960-1972)$ & $\begin{array}{l}.223 * \\
(2.10)\end{array}$ & & & & $\begin{array}{l}-.007 \\
(-.28)\end{array}$ & $\begin{array}{l}.782 * \\
(7.26)\end{array}$ & .993 & 1.476 & $\begin{array}{l}(7,42) \\
810.5\end{array}$ & -.19 & .0230 \\
\hline 2.14 & (1960-1976 III) & $\begin{array}{c}.068 \\
(.878)\end{array}$ & & & & $\begin{array}{l}-.001^{*} \\
(-2.04)\end{array}$ & $\begin{array}{l}.945^{*} \\
(7.33)\end{array}$ & .995 & 1.187 & $\begin{array}{c}(6,58) \\
1886.1\end{array}$ & -.37 & .0241 \\
\hline 2.15 & $(1960-1979)$ & $\begin{array}{l}.167^{*} \\
(2.22)\end{array}$ & & & & $\begin{array}{l}-.001^{*} \\
(-2.97)\end{array}$ & $\begin{array}{c}.860 * \\
(11.39)\end{array}$ & .995 & .565 & $\begin{array}{c}(7,70) \\
1802.0\end{array}$ & -.238 & .0280 \\
\hline
\end{tabular}

* Significativo al 5\% de confianza. 
CUADRO 3

Estimación de la Ecuación (14) (Cont.)

(ajuste real)

Variable Dependiente $\mathrm{M}_{1} / \mathrm{P}$

\begin{tabular}{|c|c|c|c|c|c|c|c|c|c|c|c|}
\hline Ecuación & Período & $y_{t}^{c}$ & $\mathrm{RT}_{\mathrm{t}}$ & $\mathrm{RL}_{\mathrm{t}}$ & $\mathrm{RNL}_{\mathrm{t}}$ & $\mathrm{m}_{\mathrm{t}-1}$ & $\mathrm{R}_{2}$ & Durbin-h & $\mathrm{F}(.,)$. & $\mathrm{R}_{\mathrm{o}}$ & Error \\
\hline 3.1 & $(1960-1972)$ & $\begin{array}{l}.232 * \\
(2.33)\end{array}$ & & $\begin{array}{l}-.043 \\
(-.45)\end{array}$ & $\begin{array}{l}-.123^{*} \\
(-1.76)\end{array}$ & $\begin{array}{c}.794^{*} \\
(7.76)\end{array}$ & .994 & .900 & $\begin{array}{l}(7,42) \\
910.5\end{array}$ & -.31 & .0223 \\
\hline 3.2 & (1960-1976 III) & $\begin{array}{l}.171 * \\
(2.53)\end{array}$ & & $\begin{array}{l}-.092 * \\
(-2.03)\end{array}$ & $\begin{array}{l}-.095^{*} \\
(-3.08)\end{array}$ & $\begin{array}{l}.861 * \\
(13.4)\end{array}$ & .996 & .474 & $\begin{array}{c}(7,57) \\
1791.1\end{array}$ & -.46 & .0231 \\
\hline 3.3 & (1960-1979) & $\begin{array}{l}.257 * \\
(3.31)\end{array}$ & & $\begin{array}{l}-.018 \\
(-.42)\end{array}$ & $\begin{array}{l}-.027 \\
(-.91)\end{array}$ & $\begin{array}{c}.759 * \\
(10.33)\end{array}$ & .994 & .565 & $\begin{array}{c}(7,70) \\
1611.2\end{array}$ & -.17 & .0297 \\
\hline 3.4 & $(1960-1972)$ & $\begin{array}{l}.260 * \\
(2.61)\end{array}$ & $\begin{array}{l}-.172 * \\
(-2.27)\end{array}$ & & & $\begin{array}{l}.777^{*} \\
(7.96)\end{array}$ & .993 & 2.450 & $\begin{array}{c}(7,42) \\
1026.8\end{array}$ & -.31 & .0220 \\
\hline 3.5 & (1960-1976 III) & $\begin{array}{l}.182 * \\
(2.59)\end{array}$ & $\begin{array}{c}-.153^{*} \\
(-3.2)\end{array}$ & & & $\begin{array}{c}.853^{*} \\
(12.93)\end{array}$ & .995 & .562 & $\begin{array}{c}(7,57) \\
2050.3\end{array}$ & -.43 & .0231 \\
\hline 3.6 & (1960-1979) & $\begin{array}{l}.245^{*} \\
(3.09)\end{array}$ & $\begin{array}{c}.001 \\
(-.35)\end{array}$ & & & $\begin{array}{c}.759 * \\
(10.21)\end{array}$ & .994 & .452 & $\begin{array}{c}(6,71) \\
1885.0\end{array}$ & -.14 & .0296 \\
\hline 3.7 & $(1960-1972)$ & $\begin{array}{l}.200 * \\
(2.00)\end{array}$ & & $\begin{array}{c}-.125 \\
(-1.47)\end{array}$ & & $\begin{array}{l}.829 * \\
(8.11)\end{array}$ & .993 & 1.200 & $\begin{array}{c}(7,42) \\
1013.6\end{array}$ & -.29 & .0224 \\
\hline 3.8 & (1960-1976 III) & $\begin{array}{l}.156^{*} \\
(2.08)\end{array}$ & & $\begin{array}{l}-.085 * \\
(-1.63)\end{array}$ & & $\begin{array}{l}.855^{*} \\
(11.9)\end{array}$ & .995 & .883 & $\begin{array}{c}(7,57) \\
1845.4\end{array}$ & -.34 & .0243 \\
\hline 3.9 & (1960-1979) & $\begin{array}{l}.255^{*} \\
(3.37)\end{array}$ & & $\begin{array}{c}-.009 \\
(-.219)\end{array}$ & & $\begin{array}{c}.752^{*} \\
(10.18)\end{array}$ & .994 & 1.230 & $\begin{array}{c}(7,70) \\
1814.1\end{array}$ & -.14 & .0291 \\
\hline 3.10 & $(1960-1972)$ & $\begin{array}{l}.246^{*} \\
(2.54)\end{array}$ & & & $\begin{array}{l}-.145^{*} \\
(-2.45)\end{array}$ & $\begin{array}{l}.778 * \\
(8.07)\end{array}$ & .993 & 2.340 & $\begin{array}{l}(6,42) \\
1044.0\end{array}$ & -.32 & .0218 \\
\hline 3.11 & (1960-1976 III) & $\begin{array}{l}.156^{*} \\
(2.23)\end{array}$ & & & $\begin{array}{l}-.092 * \\
(-2.23)\end{array}$ & $\begin{array}{c}.864 * \\
(12.88)\end{array}$ & .995 & .750 & $\begin{array}{c}(7,57) \\
1986.1\end{array}$ & -.41 & .0234 \\
\hline 3.12 & (1960-1979) & $\begin{array}{l}.259 * \\
(3.34)\end{array}$ & & & $\begin{array}{l}-.213 \\
(-.80)\end{array}$ & $\begin{array}{c}.754 * \\
(10.20)\end{array}$ & .994 & .452 & $\begin{array}{c}(6,71) \\
1902.1\end{array}$ & -.15 & .0296 \\
\hline
\end{tabular}

* Significativo al 5\%. 
Pasando ahora al siguiente período 1969-1976 (III), lo primero que llama la atención es el deterioro de los coeficientes del ingreso y de las tasas de interés, y el relativo fortalecimiento de los correspondientes a la inflación. En todas las ecuaciones presentadas en el Cuadro 2 se observa el mismo patrón de comportamiento; aunque los coeficientes de las tasas de interés siguen siendo significativos, su magnitud disminuye considerablemente al pasar del primer período al segundo. A su vez, los coeficientes correspondientes al ingreso se deterioran de manera aún más considerable, ya que en tres de las ecuaciones presentadas en el Cuadro 2 pasan a ser no significativos. Aún más, examinando el Cuadro 3 es claro que el deterioro de los coeficientes del ingreso está asociado el incremento del correspondiente a la inflación, ya que al omitir esta última variable, dichos coeficientes sí resultan significativos.

La tendencia de los coeficientes del ingreso y la tasa de interés a reducirse y el de la inflación a fortalecer continúa en le siguiente período, llegando estos últimos a ser significativos en todas las estimaciones del Cuadro 2. A fin de determinar con mas precisión la estabilidad o inestabilidad estadística de las ecuaciones estimadas para los distintos períodos de los Cuadros 2 y 3 , se realizaron pruebas de Chow ${ }^{21 /}$ que se reportan en el Cuadro 4.

\section{Cuadro 4}

Estadístico-F para $\mathrm{H}_{\mathrm{o}}$ : Los Coeficientes son

Iguales en Dos Períodos Muestrales

Variables Independientes

(Ecuaciones de Cuadro 2 y 3 )

\begin{tabular}{|c|c|c|c|c|c|c|c|c|}
\hline $\begin{array}{l}\text { Período } \\
\text { Muestral }\end{array}$ & $\begin{array}{c}\text { RL, RNL, } \\
\pi\end{array}$ & $\mathrm{RT}, \pi$ & $\mathrm{RL}, \pi$ & $\mathrm{RNL}, \pi$ & $\pi$ & $\mathrm{RT}, \pi$ & $\mathrm{RL}, \pi$ & $\mathrm{RNL}, \pi$ \\
\hline 1960-1972/ & & & & & & & & \\
\hline 1960-1976 III & & & & & 1.24 & & & \\
\hline $\mathrm{F}(16,43)$ & & 1.224 & 1.117 & 1.373 & 00 & 1.390 & 1.430 & 1.591 \\
\hline $1960-1972 /$ & & & & & & & & \\
\hline $1960-1979$ & & & 2.332 & 2.535 & 2.93 & & 2.660 & 3.200 \\
\hline $\mathrm{F}(28,43)$ & & $2.486^{*}$ & $*$ & $*$ & $9^{*}$ & $3.164^{*}$ & $*$ & $*$ \\
\hline $1960-1976 \mathrm{III}$ & & & & & & & & \\
\hline $1960-1979$ & & & 3.605 & 3.708 & 3.68 & & 3.857 & 4.607 \\
\hline$F(12,59)$ & & $3.924 *$ & $*$ & $*$ & $4^{*}$ & $5.002 *$ & $*$ & $*$ \\
\hline
\end{tabular}

* Significativo al $1 \%$

211 Para un discusión de esta prueba, véase Intrilligator (1978). 
Los resultados de las pruebas son muy consistentes, aunque un tanto sorpresivos. Pese al fuerte cambio operado en el tamaño de los coeficientes cuando se comparan 1960-1972 y 1960-1976 (III), no se puede rechazar la hipótesis que estos son estadísticamente iguales en ambos períodos. En cambio, al comparar 1960-1972 con 1960-1979 sí se detecta un cambio estructural. Para asegurar la consistencia de la prueba se compararon también los coeficientes de los períodos 1960-1976 (III) con 1960-1979 que resultaron, como era de esperarse, significativamente distintos.

Lo anterior sugiere que el período inflacionario pre-devaluación, aunque afectó la magnitud de los coeficientes estimados, no operó un cambio en la demanda de dinero como lo hizo la devaluación y el nuevo período inflacionario que le sugirió.

El deterioro de los coeficientes de ingreso y de la tasa de interés, por otra parte, es probable que se deba a problemas de especificación del modelo estimado que serán analizados más adelante. Es claro, sin embargo, que la tasa de interés es una variable importante que debe ser incluida al estimar funciones de demanda de dinero para México.

\subsection{Ajuste Real vs. Ajuste Nominal: El Problema de Homogeneidad.}

La ecuación (14) estimada en la sección anterior, se deriva de un modelo de ajuste real. Una implicación importante de este tipo de modelo es que cualquier desajuste en los saldos reales provocado por cambios en el nivel de precios, será compensado de manera inmediata. Esto es, si un alza en el nivel de precios disminuye el valor de los saldos reales, los saldos nominales se incrementarán inmediatamente para compensar dicha caída.

Este modelo ha sido criticado porque no permite rezagos en el ajuste de los saldos reales causados por movimientos en los precios. En situaciones cuando los precios están cambiando rápidamente, es muy posible que el público tarde algún tiempo en darse cuenta de la erosión de sus saldos reales; además, el ajustarlos instantáneamente tiene un costo, por lo que cabe esperar un cierto rezago $\underline{22 /}$.

Una hipótesis de comportamiento alternativa da lugar al llamado ajuste nominal:

22/ S. Goldfeld (1973) y (1976) es quien más ha insistido sobre este punto. Véanse también los artículos de W. White (1979) y W. Hafter y S. Hein (1980). 


$$
\begin{aligned}
& \ln \mathrm{M}_{\mathrm{t}}-\ln \mathrm{M}_{\mathrm{t}-1}=\gamma\left(\ln \mathrm{M}_{\mathrm{t}}^{*}-\ln \mathrm{M}_{\mathrm{t}-1}\right) \\
& \ln \mathrm{M}_{\mathrm{t}}^{*}=\mathrm{a}_{0}+\mathrm{a}_{1} \ln \mathrm{y}_{\mathrm{t}}^{\mathrm{c}}+\mathrm{a}_{2} \ln \mathrm{r}_{\mathrm{t}}^{\mathrm{c}}+\varepsilon_{\mathrm{t}}
\end{aligned}
$$

Tomando en cuenta que $\ln M_{t}^{*}-\ln P_{t}$, si se sustituye (6') en (15) obtenemos:

$$
\begin{aligned}
& \ln \mathrm{M}_{\mathrm{t}}=\gamma \mathrm{a}_{0}+\gamma \mathrm{a}_{1} \ln \mathrm{y}_{\mathrm{t}}^{\mathrm{c}}+\gamma \mathrm{a}_{2} \ln \mathrm{r}_{\mathrm{t}}^{\mathrm{c}}+\gamma \ln \mathrm{P}_{\mathrm{t}} \\
& +(1-\gamma) \ln \mathrm{M}_{\mathrm{t}-1}+\gamma \varepsilon_{\mathrm{t}}
\end{aligned}
$$

Sustrayendo el término $\ln \mathrm{P}_{\mathrm{t}}$ de ambos lados de la ecuación (16) se obtiene:

$$
\begin{aligned}
& \ln \mathrm{M}_{t}=\gamma \mathrm{a}_{0}+\gamma \mathrm{a}_{1} \ln \mathrm{y}_{\mathrm{t}}^{\mathrm{c}}+\gamma \mathrm{a}_{2} \ln \mathrm{r}_{\mathrm{t}}^{\mathrm{c}} \\
& +(1-\gamma) \ln \frac{\mathrm{M}_{\mathrm{t}-1}}{\mathrm{P}_{\mathrm{t}}}+\gamma \varepsilon_{\mathrm{t}}
\end{aligned}
$$

La diferencia entre las ecuaciones (14) y (17) es que el alza de precios afecta de manera conceptualmente distinta la demanda de dinero. La ecuación (14) se deriva de un modelo

$$
\mathrm{m}^{*}=\mathrm{f}_{1}\left(\mathrm{y}_{\mathrm{t}}^{\mathrm{c}}, \mathrm{r}_{\mathrm{t}}^{\mathrm{c}}, \pi^{*}\right)
$$

en el que las expectativas inflacionarias afectan directamente el monto de dinero deseado, modelo que se combina con una ecuación de ajuste real que supone una adaptación instantánea de saldos nominales. Por su parte, la ecuación (17) supone que

$$
\mathrm{m}^{*}=\mathrm{f}_{2}\left(\mathrm{y}_{\mathrm{t}}^{\mathrm{c}}, \mathrm{r}_{\mathrm{t}}^{\mathrm{c}}\right)
$$

pero que el público no ajusta instantáneamente la cantidad nominal de dinero ante cambios en precios para conservar sus saldos reales. 
La ecuación (17) se estimó para los períodos (1960-1972) y 1960-1976 (III) con el fin de captarse los efectos del período inflacionario pre-devaluación. En el Cuadro 5 se presentan las estimaciones para M1 en las que se utilizaron las tres tasas de interés consideradas en este trabajo.

A priori, se esperaría que las estimaciones correspondientes al período inflacionario mejoraran con el ajuste nominal, ya que el rezago correspondiente a este último tipo de ajuste permite que los cambios en los precios influyan cuando se ajustan los saldos reales corrientes a los deseados.

Comparando los Cuadro 3 y 5 se observa que, paradójicamente, el ajuste nominal funciona mejor (aunque sólo marginalmente) que el ajuste real para el período estable. Por ejemplo, los coeficientes estimados de las ecuaciones (3.4) y (5.1) muy parecido, al igual que las otras características de las regresiones. Las ecuaciones estimadas para las tasas de líquidos y no líquidos difieren también bastante poco, resultado ligeramente mejores (en términos de errores estándar) los correspondientes al cuadro 5 de ajuste nominal. Sin embargo, cuando se comparan las estimaciones para 1960-1976(III), los coeficientes de la ecuación (17) se deterioran rápidamente, contrario a lo que podría esperarse a priori.

Lo anterior sugiere que la ecuación (17) está mal especificada, ya que se ha omitido explícitamente la variable de expectativas de inflación que tiene un efecto importante en los últimos dos períodos considerados. Para corregir este problema, se realizaron algunas pruebas añadiendo la inflación corriente a dicha ecuación, pero no se obtuvieron resultados satisfactorios, lo cual indica que el error de especificación puede incluir precisamente la variable utilizada para medir expectativas de inflación. 


\section{CUADRO 5}

Estimación de la Ecuación (17)

(ajuste nominal)

Variable Dependiente $\mathrm{M}_{1} / \mathrm{P}$

\begin{tabular}{|c|c|c|c|c|c|c|c|c|c|c|c|}
\hline Ecuación & Período & $y_{t}^{c}$ & $\mathrm{RT}_{\mathrm{t}}$ & $\mathrm{RNL}_{\mathrm{t}}$ & $\mathrm{RL}_{\mathrm{t}}$ & $\mathrm{m}_{\mathrm{t}-1}$ & $\mathrm{R}_{2}$ & Durbin-h & $\mathrm{F}(.,)$. & $\mathrm{R}_{\mathrm{o}}$ & $\begin{array}{c}\text { Error } \\
\text { Estándar }\end{array}$ \\
\hline 5.1 & $(1960-1972)$ & $\begin{array}{l}.267 * \\
(2.67)\end{array}$ & $\begin{array}{l}-.178 * \\
(-2.31)\end{array}$ & & & $\begin{array}{l}.733^{*} \\
(7.85)\end{array}$ & .993 & 2.286 & $\begin{array}{c}(7,42) \\
1035.7\end{array}$ & -.227 & .0219 \\
\hline 5.2 & (1960-1976 III) & $\begin{array}{l}.1281 \\
(1.40)\end{array}$ & $\begin{array}{l}-.058 \\
(.997)\end{array}$ & & & $\begin{array}{c}.911 * \\
(10.53)\end{array}$ & .994 & .609 & $\begin{array}{c}(7,57) \\
1764.4\end{array}$ & -.280 & 0.249 \\
\hline 5.3 & $(1960-1972)$ & $\begin{array}{l}.255^{*} \\
(2.60)\end{array}$ & & $\begin{array}{l}-.165^{*} \\
(-2.42)\end{array}$ & & $\begin{array}{l}.771 * \\
(7.87)\end{array}$ & .993 & 1.200 & $\begin{array}{c}(7,42) \\
1640.8\end{array}$ & -.280 & .0218 \\
\hline 5.4 & (1960-1976 III) & $\begin{array}{c}.106 \\
(1.18)\end{array}$ & & $\begin{array}{c}.014 \\
(-.361)\end{array}$ & & $\begin{array}{c}.924^{*} \\
(10.64)\end{array}$ & .994 & .883 & $\begin{array}{c}(7,57) \\
1738.7\end{array}$ & -.270 & .0201 \\
\hline 5.5 & $(1960-1972)$ & $\begin{array}{l}.188 * \\
(1.91)\end{array}$ & & & $\begin{array}{c}.166^{*} \\
(-1.97)\end{array}$ & $\begin{array}{c}.851 * \\
(112.2)\end{array}$ & .993 & 2.388 & $\begin{array}{c}(7,47) \\
1044.0\end{array}$ & .370 & .0215 \\
\hline 5.6 & (1960-1976 III) & $\begin{array}{c}.063 \\
(.856)\end{array}$ & & & $\begin{array}{c}.139 * \\
(-2.93)\end{array}$ & $\begin{array}{c}.979 * \\
(13.15)\end{array}$ & .995 & .750 & $\begin{array}{c}(7,57) \\
1967.4\end{array}$ & -.410 & .0236 \\
\hline
\end{tabular}

* Significativo al 5\% 
3.3 La Definición de Dinero.

Un tema recurrente en la discusión sobre demanda de dinero es precisamente la definición del propio agregado monetario. Tanto para fines de política económica directos, como para utilizar de la mejor manera la demanda de dinero en la construcción de modelos macroeconómicos, es importante examinar el comportamiento de agregados monetarios alternativos. La cuestión de estabilidad de los agregados pueden examinarse separando la definición básica de $\mathrm{M}_{1}$ en sus componentes (billetes y monedas), o bien añadiendo otros pasivos bancarios que son sustitutos cercanos del dinero.

Una cuestión relacionada a este tema que es relevante para el caso de México debido al carácter institucional del sistema bancario es si se comportan de manera distinta los pasivos monetarios de la banca privada y de la banca nacional.

El Cuadro 6 incluye estimaciones de la ecuación (14) desagregando $\mathrm{M}_{1}$ en billetes y monedas y depósitos en cuenta corriente, separando asimismo los depósitos de la banca privada y mixta del total.

Los resultados del Cuadro 6 indican que los billetes y monedas responden en los tres períodos de variaciones en la tasa de interés sobre pasivos líquidos, mientras que la elasticidad de las cuentas de cheques con respecto a dicha tasa no son significativas. Se hicieron, asimismo, pruebas con las otras dos tasas de interés (la de no líquidos y la total), y las estimaciones no mostraron ninguna regularidad. Aun más, las ecuaciones correspondientes al período estable (1960-1972) son más débiles cuando se separan los componentes (en términos de errores estándar de estimación y de significación estadística de los coeficientes) que cuando se realizan estimaciones para el agregado (presentadas en el Cuadro 2). De aquí se concluye que no parece conveniente separar $\mathrm{M}_{1}$ en billetes y monedas y cuentas de cheques y estimarlas separadamente $\underline{23}$.

23/ La misma conclusión la obtuvo Gómez Oliver (1976) con sus estimaciones anuales. 


\section{CUADRO 6}

Componente de $\mathrm{M}_{1}$

(ajuste nominal)

\begin{tabular}{|c|c|c|c|c|c|c|c|c|c|c|}
\hline Ecuación & $\begin{array}{c}\text { Variable Dependiente } \\
\text { y Período }\end{array}$ & $y_{t}^{c}$ & $\mathrm{RL}_{\mathrm{t}}$ & $\pi_{\mathrm{t}}$ & $\mathrm{m}_{\mathrm{t}-1}$ & $\mathrm{R}^{2}$ & Durbin-h & $\mathrm{F}(.,)$. & $\mathrm{R}_{\mathrm{o}}$ & $\begin{array}{l}\text { Error } \\
\text { Estándar }\end{array}$ \\
\hline 6.1 & $\begin{array}{l}\text { Billetes y Monedas } \\
(1960-1972)\end{array}$ & $\begin{array}{l}.283^{*} \\
(2.59)\end{array}$ & $\begin{array}{l}-.284^{*} \\
(-3.00)\end{array}$ & $\begin{array}{l}-.317^{*} \\
(-1.20)\end{array}$ & $\begin{array}{l}.753^{*} \\
(6.41)\end{array}$ & .993 & .077 & $\begin{array}{l}(7,42) \\
925.8\end{array}$ & -.25 & .0199 \\
\hline 6.2 & (1960-1976 III) & $\begin{array}{l}.106 \\
(1.13)\end{array}$ & $\begin{array}{l}-.211^{*} \\
(-3.35)\end{array}$ & $\begin{array}{l}-.111 \\
(-1.30)\end{array}$ & $\begin{array}{l}.941^{*} \\
(9.50)\end{array}$ & .994 & .226 & $\begin{array}{l}(7,57) \\
1445.5\end{array}$ & -.48 & .0249 \\
\hline 6.3 & $(1960-1979)$ & $\begin{array}{l}.052 \\
(.54)\end{array}$ & $\begin{array}{l}-.077^{*} \\
(-1.61)\end{array}$ & $\begin{array}{l}-.172^{*} \\
(-1.61)\end{array}$ & $\begin{array}{l}.982 * \\
(9.24)\end{array}$ & .992 & .469 & $\begin{array}{c}(7,70) \\
1322.7\end{array}$ & -.23 & .0337 \\
\hline 6.4 & $\begin{array}{l}\text { Cuenta de Cheques (total) } \\
(1960-1972)\end{array}$ & $\begin{array}{l}.177^{*} \\
(1.79)\end{array}$ & $\begin{array}{l}-.154 \\
(-1.03)\end{array}$ & $\begin{array}{l}-.365 \\
(-.89)\end{array}$ & $\begin{array}{l}.870^{*} \\
(8.76)\end{array}$ & .998 & 1.000 & $\begin{array}{l}(7,42) \\
501.0\end{array}$ & -.32 & .0325 \\
\hline 6.5 & (1960-1976 III) & $\begin{array}{l}.103^{*} \\
(1.39)\end{array}$ & $\begin{array}{l}-.032 \\
(-.05)\end{array}$ & $\begin{array}{l}-.168 \\
(-2.43)\end{array}$ & $\begin{array}{l}.915^{*} \\
(12.79)\end{array}$ & .992 & .297 & $\begin{array}{c}(7,57) \\
1042.0\end{array}$ & -.38 & .0308 \\
\hline 6.6 & $(1960-1979)$ & $\begin{array}{l}.264^{*} \\
(3.82)\end{array}$ & $\begin{array}{l}-.003 \\
(-.05)\end{array}$ & $\begin{array}{l}-.234^{*} \\
(-4.01)\end{array}$ & $\begin{array}{l}.775^{*} \\
(11.30)\end{array}$ & .992 & .396 & $\begin{array}{l}(7,70) \\
1206.1\end{array}$ & -.16 & .0339 \\
\hline 6.7 & $\begin{array}{l}\text { Cuenta de Cheques (B. } \\
\text { Privada) } \\
(1960-1972)\end{array}$ & $\begin{array}{l}.205^{*} \\
(2.07)\end{array}$ & $\begin{array}{l}-.177 \\
(-1.163)\end{array}$ & $\begin{array}{l}-.456 \\
(-1.062)\end{array}$ & $\begin{array}{l}.851^{*} \\
(8.54)\end{array}$ & .989 & 1.000 & $\begin{array}{l}(7,42) \\
516.9\end{array}$ & -.29 & .0322 \\
\hline 6.8 & (1960-1976 III) & $\begin{array}{l}.144^{*} \\
(1.87)\end{array}$ & $\begin{array}{l}-.016 \\
(-.22)\end{array}$ & $\begin{array}{l}-.160^{*} \\
(-2.21)\end{array}$ & $\begin{array}{c}.875^{*} \\
(11.89)\end{array}$ & .993 & .099 & $\begin{array}{c}(7,57) \\
1084.7\end{array}$ & -.29 & .0304 \\
\hline 6.9 & $(1960-1979)$ & $\begin{array}{l}.293^{*} \\
(4.14)\end{array}$ & $\begin{array}{l}-.01 \\
(.21)\end{array}$ & $\begin{array}{l}-.224 * \\
(-3.78)\end{array}$ & $\begin{array}{l}.748^{*} \\
(10.7)\end{array}$ & .992 & .339 & $\begin{array}{l}(7,70) \\
1302.4\end{array}$ & -.08 & .0330 \\
\hline
\end{tabular}

* Significativo al 5\%. 
Por otra parte, como se puede apreciar también en el mismo cuadro, los coeficientes correspondientes a los depósitos de la banca privada y mixta y los totales son muy parecidos; las pruebas formales que se realizaron en este sentidos indican que las observaciones provienen de la misma muestra, por lo que se puede utilizar indistintamente.

La situación cambia drásticamente cuando se considera un agregado más amplio. En el Cuadro 7 se presentan estimaciones de la ecuación (14) para $\mathrm{M}_{2}$, agregado que incluye $\mathrm{M}_{1}$ más pasivos no monetarios líquidos totales.

Los resultados de las estimaciones para $\mathrm{M}_{2}$ son, en general, superiores a las efectuadas para $\mathrm{M}_{1}$. Todos los coeficientes de este cuadro son significativos y tienen el signo esperado (excepto el coeficientes de $y_{t}^{c}$ de la ecuación (7.8) que no es significativo). El estadístico Durbin-h no permite rechazar la hipótesis de no-autocorrelación, y las otras características de las regresiones son bastantes aceptables. Resalta en particular el tamaño de los errores estándar de las estimaciones, que son sustancialmente para los primeros dos períodos, ver Cuadros 2 y 3 ).

Sin embargo, pese a la robustez aparente de estas estimaciones, se observan cambios importantes en la magnitud de los coeficientes cuando se comparan distintos períodos. Al igual que para $\mathrm{M}_{1}$, los coeficientes de la tasa de interés tienden a disminuir cuando se pasa del período inicial a los de la inflación, especialmente el correspondiente a la tasa total. De hecho, la tasa de interés relevante para este agregado es la de no líquidos, ya que la tasa total incluye también el rendimiento sobre líquidos que afecta $\mathrm{M}_{2}$ en sentido directo.

El coeficiente del ingreso disminuye drásticamente del primer al segundo períodos en los tres casos considerados, pero vuelve a recuperarse cuando se estima la ecuación para todo el período muestral. 
CUADRO 7

Estimaciones de la Ecuación (14)

(ajuste real)

Variable Dependiente: $\mathrm{M}_{2} / \mathrm{P}$

\begin{tabular}{|c|c|c|c|c|c|c|c|c|c|c|c|}
\hline Ecuación & Período & $y_{t}^{c}$ & $\mathrm{RT}_{\mathrm{t}}$ & $\mathrm{RNL}_{\mathrm{t}}$ & $\pi_{\mathrm{t}}$ & $\mathrm{M}_{2 \mathrm{t}-1}$ & $\mathrm{R}^{2}$ & Durbin-h & $\mathrm{F}(.,)$. & $\mathrm{R}_{\mathrm{o}}$ & $\begin{array}{c}\text { Error } \\
\text { Estándar }\end{array}$ \\
\hline 7.1 & $(1960-1972)$ & $\begin{array}{l}.183^{*} \\
(2.44)\end{array}$ & $\begin{array}{c}-.178 * \\
(2.00)\end{array}$ & & $\begin{array}{l}-.462 * \\
(-2.11)\end{array}$ & $\begin{array}{c}.908 * \\
(20.72)\end{array}$ & .999 & -.224 & $\begin{array}{c}(7,42) \\
6450.6\end{array}$ & .19 & .0138 \\
\hline 7.2 & (1960-1976 III) & $\begin{array}{l}.069 * \\
(1.92)\end{array}$ & $\begin{array}{l}-.132 * \\
(-2.74)\end{array}$ & & $\begin{array}{l}-.195 * \\
(-7.02)\end{array}$ & $\begin{array}{c}.968 * \\
(34.50)\end{array}$ & .999 & .500 & $\begin{array}{c}(7,57) \\
7234.9\end{array}$ & -.07 & .0159 \\
\hline 7.3 & $(1960-1979)$ & $\begin{array}{l}.099 * \\
(1.81)\end{array}$ & $\begin{array}{c}-.009 * \\
(-.19)\end{array}$ & & $\begin{array}{l}-.278 * \\
(-7.02)\end{array}$ & $\begin{array}{c}.939 * \\
(31.56)\end{array}$ & .998 & .551 & $\begin{array}{c}(7,70) \\
4128.6\end{array}$ & -.12 & .0281 \\
\hline 7.4 & $(1960-1972)$ & $\begin{array}{l}.165^{*} \\
(2.29)\end{array}$ & & $\begin{array}{l}-.164 * \\
(-3.23)\end{array}$ & $\begin{array}{l}-.406^{*} \\
(-1.97)\end{array}$ & $\begin{array}{c}.911 * \\
(21.83)\end{array}$ & .999 & -.149 & $\begin{array}{c}(7,42) \\
6761.5\end{array}$ & .12 & .0135 \\
\hline 7.5 & (1960-1976 III) & $\begin{array}{l}.103 * \\
(2.09)\end{array}$ & & $\begin{array}{l}-.124^{*} \\
(-3.59)\end{array}$ & $\begin{array}{l}-.180 * \\
(-3.76)\end{array}$ & $\begin{array}{c}.943 * \\
(32.68)\end{array}$ & .998 & .417 & $\begin{array}{c}(7,57) \\
7801.2\end{array}$ & -.09 & .0152 \\
\hline 7.6 & $(1960-1979)$ & $\begin{array}{l}.187 * \\
(3.65)\end{array}$ & & $\begin{array}{c}-.088 \\
(-2.15)\end{array}$ & $\begin{array}{l}-.256^{*} \\
(-6.59)\end{array}$ & $\begin{array}{c}.890 * \\
(30.03)\end{array}$ & .998 & .460 & $\begin{array}{c}(7,70) \\
4392.4\end{array}$ & -.17 & .0222 \\
\hline 7.7 & $(1960-1972)$ & $\begin{array}{l}.195 * \\
(2.52)\end{array}$ & & & $\begin{array}{l}-.004 * \\
(-1.96)\end{array}$ & $\begin{array}{c}.883^{*} \\
(19.15)\end{array}$ & .999 & .052 & $\begin{array}{c}(6.43) \\
6962.6\end{array}$ & .39 & .0144 \\
\hline 7.8 & (1960-1976 III) & $\begin{array}{c}.012 \\
(1.87)\end{array}$ & & & $\begin{array}{l}-.002 * \\
(-3.98)\end{array}$ & $\begin{array}{c}.989 * \\
(33.27)\end{array}$ & .999 & -.596 & $\begin{array}{c}(6,58) \\
7610.0\end{array}$ & .03 & .0172 \\
\hline 7.9 & $(1960-1979)$ & $\begin{array}{l}.080 * \\
(3.37)\end{array}$ & & & $\begin{array}{l}-.002 * \\
(-7.03)\end{array}$ & $\begin{array}{c}.948 * \\
(57.93)\end{array}$ & .998 & .142 & $\begin{array}{c}(6,71) \\
4827.2\end{array}$ & -.14 & .0229 \\
\hline
\end{tabular}

* Significativo al 5\%. 
Quizá lo que más sorprende de estas regresiones es que el coeficiente de $\pi \mathrm{t}$ se comporta de la misma manera que el del ingreso: primero se reduce sustancialmente para incrementarse de nuevo en el último período aunque en mucho menor proporción. En contraste, el correspondiente a $\mathrm{M}_{1}$ sigue una tendencia más lógica, ya que se incrementa a medida que aumenta la inflación.

Por otra parte, la velocidad de ajuste es sumamente lenta en todas las ecuaciones estimadas, pero sobre todo en las que incluyen solamente la inflación ( $\sin$ las tasas) y la tasa total.

Al igual que para las estimaciones de $\mathrm{M}_{1}$, se realizaron pruebas de Chow para determinar si hubo cambio estructural en la ecuación de $\mathrm{M}_{2}$ para los distintos períodos. Los estadísticos $\mathrm{F}$ correspondientes a esta prueba se reportan en el cuadro siguiente:

\section{CUADRO 8}

Estadístico-F para $\mathrm{H}_{\mathrm{o}}$ : Los coeficientes

son iguales en dos períodos muestrales

(ecuaciones del cuadro 7)

\begin{tabular}{|c|c|c|c|}
\hline \multirow{2}{*}{$\begin{array}{l}\text { Período } \\
\text { Muestral }\end{array}$} & \multicolumn{3}{|c|}{ Variables Independientes } \\
\hline & $\mathrm{RT}, \pi$ & $\mathrm{RNL}, \pi$ & $\pi$ \\
\hline 1960-1972/1960-1976 III & 2.167 & 2.026 & 1.926 \\
\hline $\begin{array}{l}F(16,43) \\
1960-1972 / 1960-1979\end{array}$ & $5.458 *$ & $5.355^{*}$ & $3.142 *$ \\
\hline $\begin{array}{l}F(28,43) \\
1960-1976 \text { III / 1960-1979 }\end{array}$ & $6.988 *$ & $7.149^{*}$ & $5.128 *$ \\
\hline $\mathrm{F}(12,59)$ & & & \\
\hline
\end{tabular}

De nuevo, el comportamiento de $\mathrm{M}_{2}$ es parecido al de $\mathrm{M}_{1}$; los resultados de la prueba mencionada detectan un cambio estructural a partir de 1976. Otro indicador del deterioro de las estimaciones es la tendencia de los errores estándar, que crecen sustancialmente en el último período considerado. 
3.4 Especificaciones Alternativas.

De las estimaciones efectuadas en las secciones anteriores para $\mathrm{M}_{1}$ y $\mathrm{M}_{2}$ resulta claro que el proceso inflacionario iniciado en los primeros años de los setentas tuvo efectos importantes sobre la demanda de dinero. Estos efectos se manifestaron en el deterioro de los coeficientes del ingreso y de las tasas de interés, y en el fortalecimiento de los coeficientes de la inflación esperada.

El modelo que se ha venido utilizando hasta ahora se deriva de un enfoque de transacciones, en el que las variables independientes que teóricamente deben ser incluidas en el modelo (ingreso, tasa de interés e inflación) comparte, si se adopta un modelo de cartera, existen razones teóricas que indican la conveniencia de sustituir las variables observadas por otras que correspondan a algún proceso de formación de expectativas por parte del público.

En el caso de México, y en vista de los resultados obtenidos hasta ahora, no es difícil argumentar a favor de utilizar variables esperadas en vez de variables observadas.

Para el período estable, en que la varianza del ingreso y de la inflación era relativamente reducida, puede pensarse que los conceptos de "ingreso permanente" e "inflación esperada" correspondían de manera mas estrecha a las variables corrientes. Sin embargo, es también muy posible que conforme la inflación se fue acelerando a partir de 1972, el mismo proceso de formación de expectativas del público se fue modificando, por lo que el incluir variables observadas como sucedáneas o "proxy" de las esperadas puede que no resulte apropiado para los dos últimos períodos considerados.

Otro factor que puede haber influido la demanda de dinero de manera importante, sobre todo a partir de principios de 1976, es el de las expectativas del público con respecto a modificaciones futuras del tipo de cambio.

Existen varias maneras de representar procesos de formación de expectativas por parte del público. Quizá el mas frecuentemente utilizado es el de expectativas adaptativas discutido con anterioridad, el cual supone que los valores esperados en el período $t$ representan un promedio ponderado (y decreciente) de observaciones de períodos anteriores. Sin embargo, en el caso del tipo de cambio esperado no es factible utilizar este método debido a que la paridad del peso permaneció fija 
durante la mayor parte del período en consideración, y después de la devaluación de 1976 sólo fluctuó por un período muy corto de tiempo.

Para el caso de tipos de cambio flexibles, una hipótesis común que se formula en la literatura es que el tipo de cambio esperado es proporcional a la diferencia entre un tipo de largo plazo o de "equilibrio" y el tipo corriente a la vista (spot). Este tipo de cambio de largo plazo es, usualmente, una versión del Teorema de la Paridad del Poder de Compra. Sin embargo, para el caso de tipos de cambio fijos, no existe una formulación teórica convencional, por lo que se ensayaron diversos procedimientos.

En los cuadro 9 a 12 se presentan diversas estimaciones de la siguiente ecuación:

$$
\begin{aligned}
& \operatorname{lnmt}=\beta_{0}+\beta_{1} \ln \mathrm{y}^{*}+\beta_{2} \ln \mathrm{r}^{*}+\beta_{3} \ln \pi^{*}+\beta_{4} \delta^{*}+\beta_{5} \mathrm{~d}_{1} \\
& +\beta_{6} d_{2}+\beta_{7} d_{3}+\beta_{8} \ln m_{t-1} \\
& \beta_{8}=1-\lambda .
\end{aligned}
$$

$\delta^{*}$ es una variable que mide expectativas de devaluación, y $\lambda$ corresponden al coeficiente de ajuste de la ecuación (7). Los valores esperados del ingreso $y^{*}$, la inflación $\pi^{*}$, la tasa de interés $\mathrm{r}^{*}$ y la evolución futura del tipo de cambio se estimaron utilizando diferentes métodos. Para las tres primeras variables se utilizó, como una primera aproximación, un enfoque de expectativas adaptativas simple de la forma:

$$
\begin{aligned}
& \mathrm{y}^{*}=\theta 1 y_{\mathrm{t}}^{\mathrm{c}}+\left(1-\theta_{1}\right) \mathrm{y}_{\mathrm{t}-1}^{\mathrm{c}} \\
& \pi^{*}=\theta_{2} \pi_{\mathrm{t}}^{\mathrm{c}}+\left(1-\theta_{2}\right) \pi_{\mathrm{t}-1}^{\mathrm{c}} \\
& \mathrm{r}^{*}=\theta_{3} r_{\mathrm{t}}^{\mathrm{c}}+\left(1-\theta_{3}\right) \mathrm{r}_{\mathrm{t}-1}^{\mathrm{c}}
\end{aligned}
$$


Se escogió el valor de los coeficientes $\theta$, que minimizaba el error estándar de la estimación correspondiente. En general, se encontró que el ingreso y la tasa de interés corrientes producían los mejores ajustes, mientras que ponderaciones bajas en el período corriente para la variable inflacionaria resultaron más adecuadas.

Para construir un índice de expectativas de devaluación $\left(\delta^{*}\right)$ se utlizaron tres indicadores:
a) el descuento a futuro del peso en el mercado de Chicago; $\underline{24}$
b) la diferencia entre el tipo de cambio real y el observado;
c) un coeficiente de dolarización.

El mercado de Chicago comenzó a operar con futuros pesos mexicanos en 1972, por lo que se realizó una primera estimación para el período suponiendo un descuento igual a cero de 1960 a 1972. Los resultados de ambas estimaciones fueron poco satisfactorios ya que el coeficiente de esta variable no resultó significativo en ninguna regresión, y los signos tampoco fueron los esperados (estas estimaciones no se reportan).

En el cuadro 9 se presentan estimaciones de la ecuación (18). Las expectativas de devaluación están representadas por la variable dtc $=$ tipo de cambio real - tipo de cambio corriente $\mathrm{e}^{25 /}$, y la inflación esperada por

$$
\pi .2 \mathrm{t}=.2 \ln \left(\frac{\mathrm{P}_{\mathrm{t}}}{\mathrm{P}_{\mathrm{t}-1}}\right)+.8 \ln \left(\frac{\mathrm{P}_{\mathrm{t}-1}}{\mathrm{P}_{\mathrm{t}-2}}\right)
$$

El coeficiente del ingreso se comporta de manera similar al de las primeras estimaciones realizadas sin incluir la variable de expectativas (cuadros 2 y 3); esto es, decrece de manera sustancial cuando se pasa del período estable a los de mayor inflación. Sin embargo, este coeficientes resultó significativamente distinto de cero en diez de las doce ecuaciones estimadas, mejorando sustancialmente los primeros resultados reportados. A su vez aunque los coeficientes de las tasas de interés se redujeron en tamaño, también se fortalecieron estadísticamente.

24/ Promedio del descuento diario de los contratos a 6 meses, tomados trimestralmente. Los contratos a 6 meses vencen en los meses de marzo, junio, septiembre y diciembre; se tomaron los promedios diarios de los nuevos contratos en dichos meses. 
Quizá el cambio más dramático fue el del coeficiente de la inflación esperada, que se redujo muy sustancialmente en comparación con las estimaciones del cuadro 2, aunque mantuvo su tendencia a incrementarse resultando significativo en el último período.

Por otra parte, el coeficiente de las expectativas de devaluación cambia de signo cuando se pasa del período estable a los inflacionarios, volviéndose la ecuación que incluye la tasa de pasivos líquidos (9.6). El tamaño del coeficiente de esta variable es muy pequeño, aunque debe recordarse que representa un índice de expectativas por lo que no tiene una interpretación económica equivalente al del resto de los coeficientes estimados.

El cuadro 10 muestra los valores del estadístico $\mathrm{F}$ correspondiente a los residuos de las ecuaciones del cuadro 9. Como puede apreciarse, no se puede rechazar la hipótesis de que no hubo cambio estructural en los períodos considerados.

25/ Ver el Anexo Estadístico para la estimación del tipo de cambio real. 


\section{CUADRO 9}

Estimaciones de la Ecuación (18) (ajuste real)

Variable dependiente $\mathrm{M}_{1} / \mathrm{U}$

\begin{tabular}{|c|c|c|c|c|c|c|c|c|c|c|c|c|c|}
\hline Ecuación & Período & $y_{t}^{c}$ & $\mathrm{RL}_{\mathrm{t}}$ & $\mathrm{RNL}_{\mathrm{t}}$ & $\mathrm{RT}_{\mathrm{t}}$ & $\pi_{.2 \mathrm{t}^{1 /}}$ & dtc & $\mathrm{m}_{\mathrm{t}-1}$ & $\mathrm{R}^{2}$ & Durbin-h & $\mathrm{F}(.,)$. & $\mathrm{R}_{\mathrm{o}}$ & $\begin{array}{c}\text { Error } \\
\text { Estándar }\end{array}$ \\
\hline 9.1 & $(1960-1972)$ & $\begin{array}{c}.281 * \\
(2.67)\end{array}$ & $\begin{array}{l}-.345^{*} \\
(-1.67)\end{array}$ & $\begin{array}{r}-.0912 \\
(.461)\end{array}$ & & $\begin{array}{c}-.002 \\
(-.848)\end{array}$ & $\begin{array}{l}.0034 * \\
(1.79)\end{array}$ & $\begin{array}{c}.760 * \\
(6.82)\end{array}$ & .9939 & 1.45 & $\begin{array}{l}(9,39) \\
702.3\end{array}$ & -.352 & .0217 \\
\hline 9.2 & (1960-1976 III) & $\begin{array}{c}.134 * \\
(1.75)\end{array}$ & $\begin{array}{l}-.093 * \\
(-2.02)\end{array}$ & $\begin{array}{l}-.065 \\
(-1.6)\end{array}$ & & $\begin{array}{c}-.0005 \\
(-.85)\end{array}$ & $\begin{array}{l}.00022 \\
(-.763)\end{array}$ & $\begin{array}{c}.902 * \\
(12.09)\end{array}$ & .9955 & 1.53 & $\begin{array}{c}(9,54) \\
1340.8\end{array}$ & -.494 & .0228 \\
\hline 9.3 & (1960-1979) & $\begin{array}{c}.081 \\
(1.30)\end{array}$ & $\begin{array}{c}-.086^{*} \\
(-2.4)\end{array}$ & $\begin{array}{c}-.0229 \\
(.815)\end{array}$ & & $\begin{array}{c}-.0021 * \\
(-5.74)\end{array}$ & $\begin{array}{c}-.00004 \\
(-.294)\end{array}$ & $\begin{array}{c}.953 * \\
(15.86)\end{array}$ & .9954 & 1.32 & $\begin{array}{c}(9,47) \\
1602.8\end{array}$ & -.524 & .0250 \\
\hline 9.4 & $(1960-1972)$ & $\begin{array}{c}.277 * \\
(2.65)\end{array}$ & $\begin{array}{l}-.227^{*} \\
(-2.39)\end{array}$ & & & $\begin{array}{l}-.0017 \\
(-.624)\end{array}$ & $\begin{array}{c}-.0023 * \\
(2.38)\end{array}$ & $\begin{array}{c}.758 * \\
(6.85)\end{array}$ & .9938 & 1.45 & $\begin{array}{c}(8,40) \\
801.84\end{array}$ & -.348 & .0216 \\
\hline 9.5 & (1960-1976 III) & $\begin{array}{c}.0779 \\
(1.12)\end{array}$ & $\begin{array}{l}-.104^{*} \\
(-2.25)\end{array}$ & & & $\begin{array}{c}-.0012 * \\
(-2.31)\end{array}$ & $\begin{array}{c}-.0002 \\
(-.76)\end{array}$ & $\begin{array}{l}.954 * \\
(13.9)\end{array}$ & .9953 & 1.13 & $\begin{array}{c}(8,55) \\
1466.6\end{array}$ & -.447 & .0231 \\
\hline 9.6 & $(1960-1979)$ & $\begin{array}{c}.105^{*} \\
(1.87)\end{array}$ & $\begin{array}{l}-.085^{*} \\
(-2.38)\end{array}$ & & & $\begin{array}{c}-.0019 * \\
(-5.96)\end{array}$ & $\begin{array}{c}- \\
.00011 *\end{array}$ & $\begin{array}{c}.935^{*} \\
(16.48)\end{array}$ & .9953 & 1.20 & $\begin{array}{c}(8,68) \\
1\end{array}$ & -.513 & .0256 \\
\hline 9.7 & $(1960-1972)$ & $\begin{array}{l}.283^{*} \\
(2.61)\end{array}$ & & $\begin{array}{l}-.118 * \\
(-1.71)\end{array}$ & & $\begin{array}{l}.00059 \\
(.222)\end{array}$ & $\begin{array}{l}.0009 \\
(.786)\end{array}$ & $\begin{array}{l}.729 * \\
(6.35)\end{array}$ & .9934 & 1.45 & $\begin{array}{l}(8.40) \\
757.2\end{array}$ & -.300 & .0222 \\
\hline 9.8 & (1960-1976 III) & $\begin{array}{c}.150 * \\
(1.86)\end{array}$ & & $\begin{array}{l}-.077 * \\
(-1.83)\end{array}$ & & $\begin{array}{l}-.0001 \\
(-.205)\end{array}$ & $\begin{array}{l}-.0003 \\
(-1.01)\end{array}$ & $\begin{array}{c}.876^{*} \\
(11.18)\end{array}$ & .9956 & 1.34 & $\begin{array}{c}(8,55) \\
1433.1\end{array}$ & -.427 & .0233 \\
\hline 9.9 & $(1960-1979)$ & $\begin{array}{c}.117^{*} \\
(1.75)\end{array}$ & & $\begin{array}{c}-.0211 \\
(.691)\end{array}$ & & $\begin{array}{c}-.0018 * \\
(-4.37)\end{array}$ & $\begin{array}{c}-.00019 \\
(-1.29)\end{array}$ & $\begin{array}{c}.908^{*} \\
(14.30)\end{array}$ & .9950 & 1.32 & $\begin{array}{c}(8,68) \\
1699.7\end{array}$ & -.427 & .0265 \\
\hline 9.10 & $(1960-1972)$ & $\begin{array}{l}.302^{*} \\
(2.75)\end{array}$ & & & $\begin{array}{c}-.138 \\
(-1.58)\end{array}$ & $\begin{array}{l}.0005 \\
(.185)\end{array}$ & $\begin{array}{l}.0011 \\
(.957)\end{array}$ & $\begin{array}{l}.720 * \\
(6.23)\end{array}$ & .9934 & 1.45 & $\begin{array}{l}(8.40) \\
751.3\end{array}$ & -.287 & .0223 \\
\hline 9.11 & (1960-1976 III) & $\begin{array}{l}.170^{*} \\
(2.1)\end{array}$ & & & $\begin{array}{l}-.131 * \\
(-2.26)\end{array}$ & $\begin{array}{l}-.0001 \\
(-.252)\end{array}$ & $\begin{array}{l}-.0003 \\
(-1.03)\end{array}$ & $\begin{array}{c}.867 * \\
(11.29)\end{array}$ & .9954 & 1.03 & $\begin{array}{c}(8,55) \\
1\end{array}$ & -.446 & .0230 \\
\hline 9.12 & $(1960-1979)$ & $\begin{array}{c}.120^{*} \\
(1.82)\end{array}$ & & & $\begin{array}{c}-.0236 \\
(.672)\end{array}$ & $\begin{array}{c}-.0017 * \\
(-4.98)\end{array}$ & $\begin{array}{c}-.0002 \\
(-1.3)\end{array}$ & $\begin{array}{c}.904 * \\
(14.52)\end{array}$ & .9950 & 1.32 & $\begin{array}{c}(8,68) \\
1699.2\end{array}$ & -.421 & .0265 \\
\hline
\end{tabular}

* Significativo al 5\%.

$\underline{1} / \pi_{.2 \mathrm{t}}=.2 \ln \left(\frac{\mathrm{P}_{\mathrm{t}}}{\mathrm{P}_{\mathrm{t}-1}}\right)+.8 \ln \left(\frac{\mathrm{P}_{\mathrm{t}-1}}{\mathrm{P}_{\mathrm{t}-2}}\right)$ 
CUADRO 10

Estadístico-F para $\mathrm{H}_{\mathrm{o}}$ : Los Coeficientes son

Iguales en Dos Períodos Muestrales

Variables Independientes

(Ecuaciones del cuadro 9)

\begin{tabular}{|c|c|c|c|c|}
\hline \multirow{2}{*}{$\begin{array}{l}\text { Período } \\
\text { Muestral }\end{array}$} & \multirow{2}{*}{ Valor Crítico 1 / } & \multicolumn{3}{|c|}{ Variables Independientes } \\
\hline & & $\mathrm{RT}, \pi_{.2}, \mathrm{dtc}$ & $\mathrm{RL}, \pi_{.2}, \mathrm{dtc}$ & $\mathrm{RNL}, \pi_{.2}, \mathrm{dtc}$ \\
\hline $\begin{array}{l}1960-1972 / \\
1960-1976 \text { III } \\
\text { F(15,40) }\end{array}$ & & & & \\
\hline $\begin{array}{l}1960-1972 / \\
1960-1979 \\
\mathrm{~F}(28,40)\end{array}$ & 3.13 & 1.2432 & 1.5432 & 1.3902 \\
\hline $\begin{array}{l}\text { 1960-1976 III/ } \\
1960-1979\end{array}$ & 2.30 & 2.0128 & 2.0182 & 2.0411 \\
\hline & 3.34 & 2.7205 & 2.2351 & 2.5236 \\
\hline
\end{tabular}

$\underline{1 / \mathrm{Al} 1 \% .}$

La caída en los coeficientes del ingreso y la tasa de interés se vio compensada por un reducción en la velocidad de ajuste, como lo muestran las elasticidades de largo plazo del cuadro 11. Aún más, la elasticidad ingreso de largo plazo parece incrementarse en lugar de disminuir, mientras que la reducción de las elasticidades-rendimiento es, obviamente, menos pronunciada. La reducción parece ser intuitivamente lógica. Al incrementarse el ritmo de crecimiento de los precios, también aumenta la varianza de la inflación y la incertidumbre asociada con ésta, de manera que parece razonable el aceptar una reacción más lenta por parte del público. El aumento de la elasticidad ingreso, por otra parte, parece más dudoso de justificar teóricamente ya que existen fuerzas opuestas que operan cuando aumenta la incertidumbre ya mencionado, que tiene el efecto de aumentar la demanda de dinero para transacciones. La segunda, es que aumenta el costo de oportunidad de mantener dinero y, por lo tanto, baja la demanda. Parece ser, sin embargo, que este último efecto es poco importante empíricamente. 
CUADRO 11

Elasticidades de Largo Plazo

\begin{tabular}{|c|c|c|c|c|c|}
\hline Período y Ecuación & $y_{t}^{c}$ & $\mathrm{RL}_{\mathrm{t}}$ & $\mathrm{RNL}_{\mathrm{t}}$ & $\mathrm{RT}_{\mathrm{t}}$ & $\pi_{.2 \mathrm{t}}$ \\
\hline$-1972(9.4)$ & 1.14 & .93 & & & $.007^{*}$ \\
\hline -1976 III (9.5) & $1.67 *$ & 2.26 & & & .026 \\
\hline$-1979(9.6)$ & 1.41 & 1.30 & & & .029 \\
\hline$-1972(9.7)$ & 1.04 & & .435 & & $.002 *$ \\
\hline -1976 III (9.8) & 1.20 & & .620 & & $.004 *$ \\
\hline$-1979(9.9)$ & 1.22 & & $.230^{*}$ & & .019 \\
\hline$-1972(9.10)$ & 1.07 & & & .492 & $.001 *$ \\
\hline -1976 III (9.11) & 1.27 & & & .984 & $.007 *$ \\
\hline$-1979(9.12)$ & 1.25 & & & $.239^{*}$ & .017 \\
\hline
\end{tabular}

* No significativo (al 5\%).

Los cuadros 12 y 14 presentan estimaciones de la misma ecuación (18) con definiciones alternativas de inflación esperada y expectativas de devaluación. En el cuadro 12 se incluye una variable de dolarización para representar el riesgo cambiario. Dicha variable $(\mathrm{cme}=$ pasivos no monetarios en moneda extranjera/pasivos no monetarios en moneda nacional) se comporta de manera un tanto irregular, ya que se vuelve positiva en las estimaciones hechas para el último período con las tasas de instrumentos no líquidos y con la tasa total. Sin embargo, en las ecuaciones $12.4-12.6$ que incluyen la tasa sobre pasivos líquidos, cme es negativa en los tres períodos.

En el cuadro 13 aparecen los estadísticos F calculados para las ecuaciones del cuadro 12, con el objeto de verificar si hubo cambio estructural. De nuevo, aplicando la prueba de Chow no se puede rechazar la hipótesis de que los coeficientes de los distintos subperíodos no son estadísticamente distintos. Estos resultados, sin embargo, deben interpretarse con cuidado debido a que los estadísticos Durbin-h son bastante altos indicando la presencia de correlación seriada de primer orden que, en este caso, puede producir estimadores ineficientes e inconsistentes debido a la presencia de la variable endógena rezagada.

La ecuación (18) se estimó también para $\mathrm{M}_{2}$, y los resultados se muestran en el cuadro 16. Las regresiones más relevantes para este agregado son, desde luego, las tres primeras (16.1-16.3) en 
CUADRO 12

Estimaciones de la Ecuación (18) (ajuste real)

Variable dependiente $\mathrm{M}_{1} / \mathrm{P}$

\begin{tabular}{|c|c|c|c|c|c|c|c|c|c|c|c|c|c|}
\hline Ecuación & Período & $\mathrm{y}_{\mathrm{t}}^{\mathrm{c}}$ & $\mathrm{RL}_{\mathrm{t}}$ & $\mathrm{RNL}_{\mathrm{t}}$ & $\mathrm{RT}_{\mathrm{t}}$ & $\pi_{.2 \mathrm{t}} \underline{\underline{1}}$ & cme & $\mathrm{m}_{\mathrm{t}-1}$ & $\mathrm{R}^{2}$ & Durbin & $\mathrm{F}(.,)$. & $\mathrm{R}_{\mathrm{o}}$ & Error \\
\hline 12.1 & $(1960-1972)$ & $\begin{array}{l}.217^{*} \\
(2.11)\end{array}$ & $\begin{array}{c}-.106 \\
(-.814)\end{array}$ & $\begin{array}{c}-.104 \\
(1.32)\end{array}$ & & $\begin{array}{c}-.0006 * \\
(-1.98)\end{array}$ & $\begin{array}{c}-.165 \\
(-.614)\end{array}$ & $\begin{array}{l}.713 * \\
(5.94)\end{array}$ & .9938 & 3.12 & $\begin{array}{l}(9,39) \\
702.3\end{array}$ & -.314 & .0219 \\
\hline 12.2 & (1960-1976 III) & $\begin{array}{l}.134 * \\
(1.75)\end{array}$ & $\begin{array}{l}-.155^{*} \\
(-2.13)\end{array}$ & $\begin{array}{l}-.0429 \\
(-.938)\end{array}$ & & $\begin{array}{l}-.0004 \\
(-.797)\end{array}$ & $\begin{array}{c}-.077 \\
(-1.03)\end{array}$ & $\begin{array}{c}.89 * \\
(11.93)\end{array}$ & .9956 & 1.64 & $\begin{array}{c}(9,54) \\
1\end{array}$ & -.502 & .0227 \\
\hline 12.3 & $(1960-1979)$ & $\begin{array}{l}.124^{*} \\
(1.86)\end{array}$ & $\begin{array}{c}-.071 \\
(-1.38)\end{array}$ & $\begin{array}{l}-.0069 \\
(-.182)\end{array}$ & & $\begin{array}{c}-.002 * \\
(-5.9)\end{array}$ & $\begin{array}{c}-.043 \\
(-1.09)\end{array}$ & $\begin{array}{c}.936^{*} \\
(16.11)\end{array}$ & .9954 & 2.00 & $\begin{array}{c}(9,67) \\
1\end{array}$ & -.535 & .0256 \\
\hline 12.4 & $(1960-1972)$ & $\begin{array}{l}.165^{*} \\
(1.71)\end{array}$ & $\begin{array}{l}-.220 * \\
(-2.21)\end{array}$ & & & $\begin{array}{c}-.002 \\
(-.809)\end{array}$ & $\begin{array}{l}-.193 * \\
(-1.92)\end{array}$ & $\begin{array}{l}.758 * \\
(6.52)\end{array}$ & .9935 & 3.14 & $\begin{array}{l}(8,40) \\
763.1\end{array}$ & -.321 & .0221 \\
\hline 12.5 & (1960-1976 III) & $\begin{array}{l}.0669 \\
(1.00)\end{array}$ & $\begin{array}{l}-.187 * \\
(-2.89)\end{array}$ & & & $\begin{array}{l}-.0007 \\
(-1.26)\end{array}$ & $\begin{array}{l}-.111 * \\
(-1.71)\end{array}$ & $\begin{array}{c}.907 * \\
(12.57)\end{array}$ & .9955 & 1.75 & $\begin{array}{c}(8,55) \\
1\end{array}$ & -.505 & .0227 \\
\hline 12.6 & $(1960-1979)$ & $\begin{array}{l}.117^{*} \\
(2.15)\end{array}$ & $\begin{array}{l}-.072 * \\
(-2.06)\end{array}$ & & & $\begin{array}{l}-.002 * \\
(-6.15)\end{array}$ & $\begin{array}{c}-.038 \\
(-1.55)\end{array}$ & $\begin{array}{c}.939 * \\
(16.82)\end{array}$ & .9954 & 2.00 & $\begin{array}{c}(8,68) \\
1\end{array}$ & -.536 & .0254 \\
\hline 12.7 & $(1960-1972)$ & $\begin{array}{l}.256^{*} \\
(2.58)\end{array}$ & & $\begin{array}{l}-.148 * \\
(-2.42)\end{array}$ & & $\begin{array}{l}.0009 \\
(.396)\end{array}$ & $\begin{array}{c}-.145 \\
(-1.47)\end{array}$ & $\begin{array}{l}.670 * \\
(5.70)\end{array}$ & .9937 & 2.99 & $\begin{array}{l}(8.40) \\
784.7\end{array}$ & -.271 & .0218 \\
\hline 12.8 & (1960-1976 III) & $\begin{array}{l}.151 * \\
(1.88)\end{array}$ & & $\begin{array}{l}-.088 * \\
(-2.06)\end{array}$ & & $\begin{array}{l}-.0006 \\
(-.940)\end{array}$ & $\begin{array}{l}-.0462 \\
(-.939)\end{array}$ & $\begin{array}{c}.901 * \\
(11.63)\end{array}$ & .9952 & 1.94 & $\begin{array}{c}(8,55) \\
1\end{array}$ & -.462 & .0234 \\
\hline 12.9 & $(1960-1979)$ & $\begin{array}{l}.164^{*} \\
(2.39)\end{array}$ & & $\begin{array}{c}-.0204 \\
(-\end{array}$ & & $\begin{array}{c}-.0019 * \\
(-5.23)\end{array}$ & $\begin{array}{c}-.0769 * \\
(-2.03)\end{array}$ & $\begin{array}{c}.908 * \\
(15.08)\end{array}$ & .9952 & 2.11 & $\begin{array}{c}(8,68) \\
1\end{array}$ & -.473 & .0261 \\
\hline 12.10 & $(1960-1972)$ & $\begin{array}{l}.271 * \\
(2.69)\end{array}$ & & & $\begin{array}{c}-.188 * \\
(-2.4)\end{array}$ & $\begin{array}{l}.0008 \\
(.320)\end{array}$ & $\begin{array}{l}-.165 * \\
(-1.66)\end{array}$ & $\begin{array}{l}.657^{*} \\
(5.54)\end{array}$ & .9937 & 2.99 & $\begin{array}{l}(8.55) \\
783.7\end{array}$ & -.258 & .0191 \\
\hline 12.11 & (1960-1976 III) & $\begin{array}{l}.161 * \\
(2.01)\end{array}$ & & & $\begin{array}{l}-.131 * \\
(-2.77)\end{array}$ & $\begin{array}{c}-.0005 \\
(-.8)\end{array}$ & $\begin{array}{c}-.018 \\
(-.381)\end{array}$ & $\begin{array}{c}.885^{*} \\
(11.23)\end{array}$ & & & $\begin{array}{c}(8,55) \\
1\end{array}$ & -.464 & .0232 \\
\hline 12.12 & $(1960-1979)$ & $\begin{array}{l}.159 * \\
(2.38)\end{array}$ & & & $\begin{array}{c}-.0193 \\
(-.44)\end{array}$ & $\begin{array}{c}-.0019 * \\
(-5.44)\end{array}$ & $\begin{array}{c}-.073 * \\
(2.03)\end{array}$ & $\begin{array}{c}.912 * \\
(15.38)\end{array}$ & .9952 & 2.11 & $\begin{array}{c}(8,68) \\
1\end{array}$ & -.477 & .0261 \\
\hline
\end{tabular}

* Significativo al 5\%.

$\underline{1} / \pi_{.2 \mathrm{t}}=.2 \ln \left(\frac{\mathrm{P}_{\mathrm{t}}}{\mathrm{P}_{\mathrm{t}-1}}\right)+.8 \ln \left(\frac{\mathrm{P}_{\mathrm{t}-1}}{\mathrm{P}_{\mathrm{t}-2}}\right)$ 
las que aparece la tasa de no líquidos como variable independiente. Comparando este cuadro con el número 7 que comprende las estimaciones anteriores para $\mathrm{M}_{2}$, puede apreciarse una reducción sustancial del coeficiente de la inflación esperada y un aumento del coeficiente de ajuste, causados probablemente por la inclusión de la variable de dolarización ${ }^{26 /}$.

\section{CUADRO 13}

Estadístico-F para $\mathrm{H}_{\mathrm{o}}$ : Los coeficientes son iguales en dos períodos muestrales (ecuaciones del cuadro 12)

\begin{tabular}{lcccc}
\hline $\begin{array}{l}\text { Período } \\
\text { Muestral }\end{array}$ & RL, RNL, cme, $\pi_{.2}$ & RT, cme, $\pi_{.2}$ & RL, cme, $\pi_{.2}$ & RNL, cme, $\pi_{.2}$ \\
\hline $\begin{array}{l}1960-1972 / \\
1960-1976 \text { III }\end{array}$ & 1.2568 & 1.1520 & 1.5485 & 1.4787 \\
F(15,40) & & & \\
$1960-1972 /$ & & & \\
$1960-1979$ & 1.7714 & 2.0401 & 2.0394 \\
F(28,40) & & & \\
$1960-1976$ III/ & & & \\
$1960-1979$ & 2.8650 & & 2.2681 & 2.3762 \\
F(13,54) & & & \\
\hline
\end{tabular}

26/ Para las estimaciones de M2, se excluyeron los pasivos líquidos en moneda nacional del coeficiente de dolarización. 


\section{CUADRO 14}

Estimaciones de la Ecuación (18) (ajuste real) Variable dependiente $\mathrm{M}_{1} / \mathrm{P}$

\begin{tabular}{|c|c|c|c|c|c|c|c|c|c|c|c|c|}
\hline Ecuación & Período & $y_{t}^{c}$ & $\mathrm{RT}_{\mathrm{t}}$ & $\mathrm{RNL}_{\mathrm{t}}$ & $\pi_{.2 \mathrm{t}^{1 /}}$ & cme & $\mathrm{m}_{\mathrm{t}-1}$ & $\mathrm{R}^{2}$ & Durbin-h & $\mathrm{F}(.,)$. & $\mathrm{R}_{\mathrm{o}}$ & $\begin{array}{c}\text { Error } \\
\text { Estándar }\end{array}$ \\
\hline 14.1 & $(1960-1972)$ & $\begin{array}{l}.095^{*} \\
(1.74)\end{array}$ & $\begin{array}{l}-.194^{*} \\
(-3.97)\end{array}$ & & $\begin{array}{l}-.003^{*} \\
(-2.16)\end{array}$ & $\begin{array}{l}-.226^{*} \\
(-3.91)\end{array}$ & $\begin{array}{c}.874 * \\
(22.03)\end{array}$ & .999 & 1.18 & $\begin{array}{c}(8,40) \\
6600.1\end{array}$ & -.11 & .0124 \\
\hline 14.2 & (1960-1976 III) & $\begin{array}{l}.087 * \\
(2.04)\end{array}$ & $\begin{array}{l}-.145^{*} \\
(-3.57)\end{array}$ & & $\begin{array}{c}-.0008^{*} \\
(-2.14)\end{array}$ & $\begin{array}{l}-.240^{*} \\
(-4.88)\end{array}$ & $\begin{array}{c}.866^{*} \\
(24.80)\end{array}$ & .999 & 1.07 & $\begin{array}{c}(8,55) \\
6835.9\end{array}$ & -.26 & .0152 \\
\hline 14.3 & $(1960-1979)$ & $\begin{array}{l}.135^{*} \\
(2.48)\end{array}$ & $\begin{array}{l}-.006 \\
(.13)\end{array}$ & & $\begin{array}{l}-.002^{*} \\
(-5.69)\end{array}$ & $\begin{array}{l}-.105^{*} \\
(-2.00)\end{array}$ & $\begin{array}{l}.871^{*} \\
(21.3)\end{array}$ & .997 & 1.34 & $\begin{array}{c}(8,68) \\
3097.6\end{array}$ & -.30 & .0240 \\
\hline 14.4 & $(1960-1972)$ & $\begin{array}{l}.081^{*} \\
(1.69)\end{array}$ & & $\begin{array}{l}-.166^{*} \\
(-4.61)\end{array}$ & $\begin{array}{l}-.003^{*} \\
(-2.08)\end{array}$ & $\begin{array}{l}-.206^{*} \\
(-3.82)\end{array}$ & $\begin{array}{l}.880^{*} \\
(23.6)\end{array}$ & .999 & .861 & $\begin{array}{c}(8,40) \\
7030.0\end{array}$ & -.10 & .0120 \\
\hline 14.5 & (1960-1976 III) & $\begin{array}{l}.102 * \\
(2.30)\end{array}$ & & $\begin{array}{l}-.113 * \\
(-3.62)\end{array}$ & $\begin{array}{l}-.008^{*} \\
(-2.03)\end{array}$ & $\begin{array}{l}-.213^{*} \\
(-4.29)\end{array}$ & $\begin{array}{l}.860^{*} \\
(24.2)\end{array}$ & .999 & 1.07 & $\begin{array}{c}(8,55) \\
6904.9\end{array}$ & -.24 & .0152 \\
\hline 14.6 & $(1960-1979)$ & $\begin{array}{l}.205^{*} \\
(4.04)\end{array}$ & & $\begin{array}{l}-.069 * \\
(-1.64)\end{array}$ & $\begin{array}{l}-.001^{*} \\
(-5.61)\end{array}$ & $\begin{array}{l}-.078^{*} \\
(-1.72)\end{array}$ & $\begin{array}{l}.844^{*} \\
(21.4)\end{array}$ & .997 & 1.24 & $\begin{array}{c}(8,65) \\
3219.8\end{array}$ & -.31 & .0235 \\
\hline
\end{tabular}

* Significativo al 5\%.

$\underline{1} / \pi_{.1 \mathrm{t}}=.1 \ln \left(\frac{\mathrm{P}_{\mathrm{t}}}{\mathrm{P}_{\mathrm{t}-1}}\right)+.9 \ln \left(\frac{\mathrm{P}_{\mathrm{t}-1}}{\mathrm{P}_{\mathrm{t}-2}}\right)$. 
Las elasticidades correspondientes a estas estimaciones se presentan a continuación.

$$
\text { CUADRO } 15
$$

Elasticidades de Largo Plazo

\begin{tabular}{lcccc}
\hline Período y Ecuación & $\mathrm{y}_{\mathrm{t}}^{\mathrm{c}}$ & $\mathrm{RT}_{\mathrm{t}}$ & $\mathrm{RNL}_{\mathrm{t}}$ & $\pi_{.1 \mathrm{t}}$ \\
\hline $1972(14.1)$ & .75 & 1.53 & & .023 \\
1976 III $(14.2)$ & .65 & 1.08 & & .005 \\
$1979(14.3)$ & 1.04 & $.04^{*}$ & & .015 \\
$1972(14.4)$ & .67 & & 1.38 & .025 \\
1976 III (14.5) & .72 & & .80 & .057 \\
$1979(14.6)$ & 1.31 & & .44 & .006 \\
\hline
\end{tabular}

* No significativo al 5\%.

Aunque no son directamente comparables las elasticidades de $\mathrm{M}_{2}$ con las reportadas para $\mathrm{M}_{1}$ en el cuadro 11 (debido a que las variables de expectativas de devaluación son distintas para ambas estimaciones) es interesante observar que las elasticidades ingreso también aumentan entre el período estable y los inflactorios. A su vez, la elasticidad de la demanda de dinero con respecto a la tasa total se deteriora bruscamente a partir de 1976, lo que se explica si se examina de nuevo la Gráfica 1. Es precisamente a partir de ese año que las tasas de líquidos y de no líquidos comienzan a moverse en sentido opuesto, de manera que la tasa total está reflejando tendencias o puestas durante 1977 y 1978.

Finalmente, se ensayó un método distinto para generar una serie de inflación esperada, consistente en un enfoque a expectativas racionales ${ }^{27 /}$. La estimación de esta serie se redujo utilizando el modelo univariado de Box y Jenkins en sus dos fases, identificación y modelaje ${ }^{28 /}$. El modelaje se logró eliminar el ruido no blanco de la serie. Los cuadros 16 y 17 muestran los resultados de estimar la ecuación 18 con esta nueva variable inflacionaria para $\mathrm{M}_{1}$ y $\mathrm{M}_{2}$; en las estimaciones correspondientes a este último agregado también se incluyó la variable de expectativas de devaluación cme.

27) Véase Sargent (1979)

28/ Los detalles de este proceso están descritos en el apéndice estadístico. 


\section{CUADRO 16}

Estimaciones de la Ecuación (18) (ajuste real) Variable dependiente $\mathrm{M}_{1} / \mathrm{P}$

\begin{tabular}{|c|c|c|c|c|c|c|c|c|c|c|c|c|}
\hline Ecuación & Período & $y_{t}^{c}$ & $\mathrm{RL}_{\mathrm{t}}$ & $\mathrm{RNL}_{\mathrm{t}}$ & $\mathrm{RT}_{\mathrm{t}}$ & $\pi^{*} \underline{1}^{*}$ & $\mathrm{~m}_{\mathrm{t}-1}$ & $\mathrm{R}^{2}$ & Durbin-h & $\mathrm{F}(.,)$. & $\mathrm{R}_{\mathrm{o}}$ & Error \\
\hline 16.1 & $(1960-1972)$ & .138 & $-.171^{*}$ & & & -.0009 & $.894 *$ & .993 & 1.116 & $(7,38)$ & .14 & .0212 \\
\hline 16.2 & (1960-1976 III) & $\begin{array}{c}(-1.47) \\
.072\end{array}$ & $\begin{array}{l}(-2.12) \\
-.122^{*}\end{array}$ & & & $\begin{array}{l}(-.49) \\
-.0003\end{array}$ & $\begin{array}{l}(9.22) \\
.941^{*}\end{array}$ & .995 & .703 & $\begin{array}{l}794.6 \\
(7,53)\end{array}$ & -.41 & .02271 \\
\hline 16.3 & (1960-1979) & $\begin{array}{l}(.95) \\
.172 *\end{array}$ & $\begin{array}{l}(-2.50) \\
-.029\end{array}$ & & & $\begin{array}{l}(-1.11) \\
-.0004\end{array}$ & $\begin{array}{c}(12.49) \\
.840^{*}\end{array}$ & .994 & .603 & $\begin{array}{c}1500.0 \\
(7,66)\end{array}$ & -.21 & .02860 \\
\hline 16.4 & $(1960-1972)$ & $\begin{array}{l}(2.32) \\
.201^{*}\end{array}$ & $(-.74)$ & $-.130 *$ & & $\begin{array}{c}(-1.54) \\
-.00004\end{array}$ & $\begin{array}{c}(11.31) \\
.813^{*}\end{array}$ & .993 & 1.2309 & $\begin{array}{c}1464.2 \\
(7,38)\end{array}$ & -.29 & .02111 \\
\hline 16.5 & (1960-1976 III) & $\begin{array}{l}(2.05) \\
.173 *\end{array}$ & & $\begin{array}{l}(-2.14) \\
-.104^{*}\end{array}$ & & $\begin{array}{c}(-.235) \\
-.00026\end{array}$ & $\begin{array}{l}(8.30) \\
.844^{*}\end{array}$ & .995 & 1.3156 & $\begin{array}{l}798.8 \\
(7,53)\end{array}$ & -.38 & .02258 \\
\hline 16.6 & (1960-1979) & $\begin{array}{l}(1.99) \\
.195^{*}\end{array}$ & & $\begin{array}{l}(-2.60) \\
-.0013\end{array}$ & & $\begin{array}{l}(-.840) \\
-.0003\end{array}$ & $\begin{array}{c}(10.06) \\
.815^{*}\end{array}$ & .994 & .5466 & $\begin{array}{c}1516.9 \\
(7,66)\end{array}$ & -.17 & .02871 \\
\hline 16.7 & $(1960-1972)$ & $\begin{array}{l}(2.35) \\
.214^{*}\end{array}$ & & $(-.043)$ & $-.167 *$ & $\begin{array}{l}(-1.078) \\
-.00002\end{array}$ & $\begin{array}{c}(10.34) \\
.813^{*}\end{array}$ & .993 & 1.1843 & $\begin{array}{c}1453.6 \\
(7,38)\end{array}$ & -.28 & .02106 \\
\hline 16.8 & (1960-1976 III) & $\begin{array}{l}(2.16) \\
.203^{*}\end{array}$ & & & $\begin{array}{l}(-2.18) \\
-.178^{*}\end{array}$ & $\begin{array}{l}(-.009) \\
-.0003\end{array}$ & $\begin{array}{l}(8.31) \\
.828^{*}\end{array}$ & .995 & 1.011 & $\begin{array}{l}802.6 \\
(7,53)\end{array}$ & -.41 & .02203 \\
\hline 16.9 & $(1960-1979)$ & $\begin{array}{l}(2.35) \\
.170^{*} \\
(2.08)\end{array}$ & & & $\begin{array}{c}(-3.16) \\
.0213 \\
(.598)\end{array}$ & $\begin{array}{c}(1.007) \\
-.0004 \\
(-1.41)\end{array}$ & $\begin{array}{c}(10.15) \\
.833^{*} \\
(10.30)\end{array}$ & .994 & .510 & $\begin{array}{c}1594.9 \\
(7,66) \\
1461.5\end{array}$ & -.18 & .02863 \\
\hline
\end{tabular}

* Significativo al 5\%.

$\underline{1} / \pi^{*}=$ Expectativas inflacionarias calculadas por Box-Jenkins (ver Anexo). 


\section{CUADRO 17}

Estimaciones de la Ecuación (18) (ajuste real)

Variable dependiente $\mathrm{M}_{2} / \mathrm{P}$

\begin{tabular}{|c|c|c|c|c|c|c|c|c|c|c|c|c|}
\hline \multicolumn{2}{|c|}{ Ecuación } & \multirow[t]{2}{*}{$y_{t}^{c}$} & \multirow[t]{2}{*}{$\mathrm{RT}_{\mathrm{t}}$} & $\mathrm{RNL}_{\mathrm{t}}$ & $\pi_{*}$ & cme & $\mathrm{m}_{\mathrm{t}-1}$ & $\mathrm{R}^{2}$ & Durbin-h & $\mathrm{F}(.,)$. & $\mathrm{R}_{\mathrm{o}}$ & $\begin{array}{c}\text { Error } \\
\text { Estándar }\end{array}$ \\
\hline 17.1 & $(1960-1972)$ & & & $-.115^{*}$ & -.0009 & $-.452^{*}$ & $.854 *$ & .999 & .860 & $(8,40)$ & -.11 & .0117 \\
\hline 17.2 & (1960-1976 III) & $\begin{array}{l}(2.24) \\
.103 *\end{array}$ & & $\begin{array}{l}(-2.88) \\
-.126^{*}\end{array}$ & $\begin{array}{c}(-.81) \\
-.0000\end{array}$ & $\begin{array}{l}(-4.58) \\
-.448^{*}\end{array}$ & $\begin{array}{l}(21.51) \\
.862^{*}\end{array}$ & .999 & 915 & $\begin{array}{c}7428.4 \\
(8,55)\end{array}$ & -.19 & .01501 \\
\hline 17.3 & $(1960-1979)$ & $\begin{array}{l}(2.37) \\
.222 *\end{array}$ & & $\begin{array}{c}(-3.89) \\
-.099\end{array}$ & $\begin{array}{c}(-.0006) \\
-.0002\end{array}$ & $\begin{array}{l}(-4.91) \\
-.227\end{array}$ & $\begin{array}{c}(24.67) \\
.818^{*}\end{array}$ & .997 & .358 & $\begin{array}{c}7 \\
(8,68)\end{array}$ & -.09 & .02689 \\
\hline 17.4 & $(1960-1972)$ & $\begin{array}{l}(2.84) \\
.136^{*}\end{array}$ & $-.115^{*}$ & $(-1.49)$ & $\begin{array}{l}(-.005) \\
-.0012\end{array}$ & $\begin{array}{l}(-1.63) \\
-.497^{*}\end{array}$ & $\begin{array}{l}(13.67) \\
.841^{*}\end{array}$ & .999 & .874 & $\begin{array}{c}2478.9 \\
(8,40)\end{array}$ & -.035 & .0112 \\
\hline 17.5 & (1960-1976 III) & $\begin{array}{l}(2.38) \\
.083^{*}\end{array}$ & $\begin{array}{l}(-2.13) \\
-.154^{*}\end{array}$ & & $\begin{array}{c}(-1.01) \\
-.00004\end{array}$ & $\begin{array}{l}(-4.71) \\
-.489 *\end{array}$ & $\begin{array}{c}(19.87) \\
.874\end{array}$ & .999 & .915 & $\begin{array}{c}7033.1 \\
(8,55)\end{array}$ & -.20 & .0153 \\
\hline 17.6 & $(1960-1979)$ & $\begin{array}{c}(1.98) \\
.079 \\
(1.05)\end{array}$ & $\begin{array}{l}(-3.61) \\
-.0818 \\
(1.112)\end{array}$ & & $\begin{array}{c}(-.256) \\
-.0003 \\
(-1.112)\end{array}$ & $\begin{array}{l}(-5.35) \\
-.329^{*} \\
(-2.31)\end{array}$ & $\begin{array}{c}(25.18) \\
.868^{*} \\
(14.54)\end{array}$ & .997 & 1.032 & $\begin{array}{c}6848.7 \\
(8,67) \\
2401.7\end{array}$ & -.13 & .0266 \\
\hline
\end{tabular}

* Significativo al 5\%. 

Quizá lo más relevante de estas estimaciones es que el coeficiente de la inflación resultó de un orden de magnitud aún inferior al de las estimaciones previas que se realizaron utilizando el método de expectativas adaptativas. Se realizaron también pruebas Chow para examinar la estabilidad de ambos agregados para los distintos períodos, pero en esta ocasión los estadísticos F sí resultaron significativos, por lo que se rechazó la hipótesis de igualdad de los coeficientes.

\section{Conclusiones, Limitaciones y Extensiones.}

i) Desde un punto de vista estrictamente empírico, una de las conclusiones más claras que se obtienen de este estudio es la importancia que tiene la tasa de interés pasiva para explicar cambios en la demanda de dinero. En contraste con los resultados obtenidos en los trabajos empíricos previos realizados sobre México, parece ser que cambios en la inflación esperada influyen de manera menos significativa en la demanda de dinero que modificaciones en la tasa de interés pasiva. Este resultado es bastante robusto, ya que se obtuvo utilizando un procedimiento de expectativas adaptativas y otro de expectativas racionales para construir las series de inflación esperada.

ii) Un segundo punto que merece ser resaltado es el comportamiento de los coeficientes de las variables ingreso, inflación y tasa de interés conforme se pasa del período estable a los inflacionarios. Los coeficientes del ingreso y de las tasas de interés se deterioran fuertemente, mientras que se fortalece el de la inflación y la velocidad de ajuste disminuye. Estos efectos se combinan produciendo elasticidades con respecto al ingreso y a la inflación que crecen durante los tres períodos, y elasticidades con respecto a las distintas tasas de interés que crecen de 1960-72 a 1960-1976 III, y luego disminuyen al pasar al último período considerado. Sin embargo, aún en este último período las elasticidades con respecto a la tasa de inflación continúan siendo de un orden de magnitud inferior.

El incremento de las elasticidades ingreso e inflación puede explicarse por la mayor incertidumbre asociada con la aceleración del incremento de los precios, mientras que la reducción de la elasticidad rendimiento quizá se deba a la posible agudización de expectativas de devaluación asociadas a la propia modificación del tipo de cambio ocurrida en 1976. De hecho, la introducción de los índices de expectativas considerados en el texto, aunque no puede decirse que resultaron muy robustos desde el punto de vista estadístico, sí mejoraron las primeras estimaciones intentadas, por lo 
que parece relevante su inclusión. Desde luego, debe seguirse trabajando para mejorar los indicadores ensayados aquí.

El promedio de la elasticidad ingreso de largo plazo calculada para los distintos períodos en las ecuaciones que incluyen la variable de expectativas de devaluación fue de 1.20; la correspondiente a la tasa de líquidos de 1.49 , la de no líquidos de .42 y la de inflación fue de .022 . El valor de la elasticidad ingreso obtenido es similar al reportado en otros estudios que se comentaron anteriormente.

iii) Las diversas pruebas realizadas indican que la desagregación de $\mathrm{M}_{1}$ en sus componentes monedas y billetes- produce resultados inferiores a los obtenidos estimando el agregado $\mathrm{M}_{1}$. Por el contrario, también es aparente que las ecuaciones estimadas para $\mathrm{M}_{2}$ son estadísticamente más robustas que las correspondientes a este agregado, pese a que se detectó la presencia de cambio estructural a partir de la devaluación.

iv) Un punto conceptual importante que se desprende de este trabajo es el relativo a la estabilidad de la función de demanda de dinero. En todos los trabajos examinados anteriormente para el caso de México, los autores concluyen que la demanda de dinero es una función estable del ingreso permanente y la tasa de inflación. Sin embargo, solamente uno de los autores se preocupa por realizar pruebas de estabilidad (G. Valdez).

Revisando las estimaciones realizadas se detectó un cambio estructural en la demanda de dinero a partir de la devaluación de 1976 en todas las ecuaciones consideradas a excepción de una de ellas, que incluye el diferencial entre el tipo de cambio real y el observado como medida del riesgo cambiario. Esto indica que resulta bastante difícil hablar de "un alto grado de estabilidad" de la función con respecto a las variables convencionales, ya que el riesgo cambiario constituye un factor de influencia muy importante que no es plenamente capturado ni por la inflación esperada ni por el comportamiento de las tasas de interés. Por otra parte, ha resultado bastante difícil diseñar un índice de expectativas de devaluación efectivo.

v) De lo anterior se desprende que el pretender obtener conclusiones de política económica basados en la estabilidad de la función es un ejercicio poco relevante. Como se mencionó en la primera parte del trabajo, aún en el caso en que se hubiera encontrado una función verdaderamente estable, 
dado el marco financiero institucional de México no es posible llegar a las conclusiones monetaristas tradicionales sobre la efectividad relativa de la política monetaria como instrumento de estabilización.

vi) Una extensión interesante del presente trabajo podría consistir en investigar el mecanismo de ajuste del mercado monetario a fin de comprobar si se justifica el estimar una ecuación de demanda, o si se requiere un modelo simultáneo. En caso de que el sesgo de simultaneidad sea poco importante, valdría la pena tratar de afinar más la medición de las variables esperadas y especialmente la de expectativas de devaluación, a fin de realizar simulaciones en el período de muestra y llegar a obtener una buena ecuación que sirva para realizar predicciones.

vii) Seguramente una extensión más interesante sería el incluir el resto de pasivos del sistema en un modelo financiero de equilibrio general que, en una primera etapa, tomaría como dadas o exógenas todas las variables relevantes del sector real. 


\section{$\underline{\text { APENDICE ESTADISTICO }}$}

1. Las variables monetarias utilizadas fueron las siguientes:

$\mathrm{M} \emptyset=$ billetes y monedas en circulación.

$\mathrm{M} \emptyset 1 \mathrm{~T}=$ cuentas de cheques en moneda nacional totales.

$\mathrm{M} \emptyset 1 \mathrm{P}=$ cuentas de cheques en moneda nacional en la Banca Privada y Mixta.

$\mathrm{M} 1 \mathrm{~T}=\mathrm{M} \emptyset+\mathrm{M} \emptyset 1 \mathrm{~T}=$ billetes y monedas + cuentas de cheques totales.

$\mathrm{M} 1 \mathrm{P}=\mathrm{M} \emptyset+\mathrm{M} \emptyset 1 \mathrm{P}=$ billetes y monedas + cuentas de cheques en la Banca Privada y Mixta.

$\mathrm{M} 21 \mathrm{~T}=\mathrm{M} 1 \mathrm{~T}+\mathrm{M} 2 \mathrm{P}=$ billetes y monedas + cuentas de cheques totales + pasivos no monetarios líquidos ${ }^{29 /}$.

$\mathrm{M} 21 \mathrm{P}=\mathrm{M} 1 \mathrm{P}+\mathrm{M} 2 \mathrm{P}=$ billetes y monedas + cuentas de cheques en la Banca Privada y Mixta + pasivos no monetarios líquidos ${ }^{1 /}$.

2. El índice de precios (IPCM) que se utilizó tanto para deflactor los pasivos monetarios como para la variable de inflación se elaboró aplicando las variaciones trimestrales del índice de precios al consumidor al deflactor implícito del PIB. En los años en que no se contaba con el índice de precios al consumidor, se utilizó el índice de estacionalidad que se observó durante los años 19681972 en los precios al consumidor. De cualquier manera, se llevaron a cabo regresiones utilizando el índice de precios al mayoreo -para el que sí se cuenta con información desde 1960- y los resultados no difirieron de los obtenidos mediante el índice elaborado a partir del de precios al consumidor.

3. La variable de ingreso (PIB1) se construyó de manera similar a la de precios descrita en el punto anterior, aplicando las variaciones trimestrales observadas durante el año en el índice de producción

29/ Los pasivos no monetarios líquidos son los depósitos a plazo con vencimiento hasta un mes. 
industrial al nivel del Producto Interno Bruto en términos reales. Debido a que el crecimiento de la producción industrial excedente al del PIB, este excedente se repartió de manera proporcional en los trimestres de cada año. De la misma manera que en el caso del índice de precios para los años en que no se contó con información del PBI se utilizó su índice de estacionalidad.

4. El tipo de cambio real (TCR) quedó definido de la siguiente manera:

$$
\mathrm{TCR}=\frac{\text { IPCMex }}{\text { IPCE.U. }} \times \frac{12.50}{\text { TCO }} \times 12.50
$$

donde: IPCMex = Indice de Precios al Consumidor en México.

IPCE.U. = Indice de Precios al Consumidor en E.U.

$\mathrm{TCO}=$ Tipo de cambio observado

Se utilizó 12.50 como base ya que todos los datos están en base $1960=100$

5. La variable (DTC ${ }^{1}$ ) (diferencial del tipo de cambio), es simplemente la diferencia porcentual entre el tipo de cambio real -descrita en el punto anterior- y el tipo de cambio observado.

6. (CME) que se utilizó también como una medida de expectativas de devaluación, es el cociente de las cuentas de cheques denominadas en moneda extranjera y los pasivos no monetarios totales en moneda nacional.

7. Se contó con tres definiciones de tasas de interés ponderadas: una sobre pasivos no monetarios líquidos (RNML); otra sobre pasivos no monetarios no líquidos (RNMNL) y la tercera una tasa ponderada total $(\mathrm{RT})$.

Todos los datos utilizados son saldos a fin de trimestre. En los listados anexos, el dato 1 corresponde al primer trimestre de 1960, y así sucesivamente hasta el número 80 que corresponde al cuarto trimestre de 1979. 
LINE 43 TIME SERIES PROCESSOR VEERSION 2.7 FEB. 1977 UNI 1106 SALI PAGE 8

\begin{tabular}{|c|c|c|c|c|c|c|c|}
\hline & & M0 & MU1T & MD1P & M1T & M1P & $\mathrm{M}<\mathrm{P}$ \\
\hline 1 & • & 6745.30 & 5257.20 & 7847.20 & 15002.9 & 14592.5 & 3646.70 \\
\hline 2 & - & 5695.48 & 8643.70 & 8124.50 & 15301.1 & 14824.9 & 3855.90 \\
\hline 3 & - & 6675.80 & 8822.50 & 8336.60 & 15656.6 & 15172.1 & 4115.40 \\
\hline 4 & • & 7874.50 & 9014.50 & 8628.10 & 16049.0 & 16562.6 & 4274.10 \\
\hline 5 & - & 7088.20 & 8980.70 & 8443.00 & 16476.9 & 16919.2 & 4494.20 \\
\hline 6 & - & 7211.50 & 9878.50 & 8646.30 & 16166.7 & 15734.5 & 4936.10 \\
\hline 7 & - & 8275.40 & 9060.70 & 8651.50 & 16272.2 & 15863.0 & 5347.90 \\
\hline 8 & • & 7803.00 & 9732.20 & 9224.70 & 18697.6 & 17500.1 & 5518.10 \\
\hline 9 & - & 7681.00 & 9499.40 & 9042.30 & 17302.4 & 16845.3 & 5682.80 \\
\hline 10 & - & 7759.90 & 9789.00 & 9191.00 & 17300.8 & 16872.7 & 5878.70 \\
\hline 11 & • & 9144.20 & 10086.3 & 9471.80 & 17765.2 & 17231.7 & 6219.00 \\
\hline 12 & - & 8542.90 & 11130.2 & 10589.1 & 22274.4 & 19733.3 & 8499.70 \\
\hline 13 & • & 8439.10 & 11140.6 & 10594.0 & 19683.3 & 19136.9 & 7018.80 \\
\hline 14 & • & 8513.00 & 11448.0 & 10932.8 & 19885.1 & 19371.9 & 7423.40 \\
\hline 15 & • & 10263.7 & 11912.0 & 11316.9 & 20425.0 & 19831.9 & 8065.90 \\
\hline 16 & • & 9419.40 & 13416.5 & 12817.6 & 23680.2 & 23981.3 & 8646.40 \\
\hline 17 & • & 9804.78 & 13911.8 & 13301.5 & 23831.2 & 23220.9 & 10233.7 \\
\hline 18 & - & 10065.5 & 13957.4 & 13407.4 & 23762.1 & 23212.1 & 11293.2 \\
\hline 19 & $\bullet$ & 11923.4 & 14868.4 & 14039.6 & 24671.9 & 24945.1 & 12225.5 \\
\hline 20 & - & 10864.1 & 15716.8 & 15084.7 & 27640.2 & 27068.1 & 13335.3 \\
\hline 21 & • & 10532.1 & 15856.1 & 15025.0 & 25720.2 & 25889.1 & 14635.4 \\
\hline 22 & - & 10436.2 & 15847.3 & 14786.2 & 26379.4 & 25614.5 & 15900.1 \\
\hline 23 & • & 12506.9 & 15404.2 & 16226.1 & 25840.4 & 25222.4 & 17135.7 \\
\hline 24 & - & 11539.3 & 17812.1 & 16249.5 & 29518.9 & 26733.0 & 18545.3 \\
\hline 25 & - & 11246.3 & 16975.1 & 16138.8 & 28514.4 & 27788.0 & 19987.6 \\
\hline 26 & - & 11246.2 & 17042.2 & 15973.4 & 28288.4 & 27385.0 & 21514.8 \\
\hline 27 & $\bullet$ & 11413.1 & 16892.8 & 18173.4 & 28305.9 & 27386.5 & 23235.1 \\
\hline 28 & - & 13629.6 & 19121.8 & 17795.8 & 32751.4 & 31808.0 & 24427.6 \\
\hline 29 & • & 12416.3 & 18660.0 & 17817.7 & 31076.3 & 30212.1 & 26521.4 \\
\hline 30 & - & 12265.7 & 18930.5 & 17355.2 & 31202.2 & 30083.4 & 27995.0 \\
\hline 31 & • & 12594.5 & 18310.7 & 19458.3 & 30905.2 & 29949.7 & 29442.4 \\
\hline 32 & - & 14748.6 & 20638.2 & 19080.8 & 35386.8 & 34206.9 & 31288.6 \\
\hline 33 & - & 14039.6 & 30077.8 & 19151.7 & 34117.1 & 33100.1 & 33088.4 \\
\hline 34 & - & 13970.5 & 20067.7 & 19383.2 & 34038.2 & 33122.2 & 34040.3 \\
\hline 35 & • & 14131.2 & 20341.4 & 22381.5 & 34472.6 & 33514.4 & 34918.2 \\
\hline 36 & - & 16674.2 & 23317.1 & 24064.9 & 39991.3 & 39065.7 & 37234.6 \\
\hline 37 & - & 15863.4 & 22187.4 & 21347.8 & 38050.8 & 36928.3 & 38782.5 \\
\hline 38 & - & 15317.3 & 22561.5 & 21400.6 & 37878.8 & 36665.1 & 38097.7 \\
\hline 39 & • & 15212.2 & 22237.8 & 25126.6 & 37450.0 & 30612.8 & 38782.5 \\
\hline 40 & - & 18245.0 & 26095.0 & 23472.4 & 44340.0 & 43371.6 & 38097.7 \\
\hline 41 & - & 17051.7 & 24917.5 & 23751.6 & 41969.2 & 40524.1 & 38782.1 \\
\hline 42 & - & 16812.6 & 24730.7 & 23566.0 & 41543.3 & 40564.2 & 38390.2 \\
\hline 43 & • & 15863.5 & 24542.0 & 20341.8 & 41056.2 & 40080.2 & 40141.4 \\
\hline 44 & • & 20143.9 & 28868.8 & 27615.3 & 49012.7 & 47759.2 & 41304.9 \\
\hline 45 & - & 18281.5 & 26172.8 & 25058.7 & 44454.3 & 43340.2 & 42216.3 \\
\hline 46 & - & 17900.5 & 26573.0 & 25172.9 & 44473.5 & 43073.4 & 44391. \\
\hline
\end{tabular}


LINE 13 TIME SERIES PROCESSOR VEERSION 2.7 FEB. 1977 UNI 1106 SALI PAGE 9

$\begin{array}{rrrrrrrr} & & \text { M0 } & \text { MU1T } & \text { MD1P } & \text { M1T } & \text { M1P } & \text { M }<\mathrm{P} \\ 47 & \bullet & 17687.3 & 26303.2 & 24730.5 & 43990.5 & 42417.8 & 46998.4 \\ 48 & \bullet & 21824.4 & 31236.0 & 29855.5 & 53660.4 & 51679.9 & 49142.7 \\ 49 & \bullet & 23642.3 & 28410.0 & 27294.8 & 50052.9 & 48937.1 & 50969.3 \\ 50 & \bullet & 20481.0 & 30608.2 & 29273.8 & 51169.2 & 49754.8 & 83854.7 \\ 51 & \bullet & 21356.7 & 38652.5 & 29335.3 & 51987.2 & 50692.0 & 56512.1 \\ 52 & \bullet & 26771.5 & 37550.3 & 35902.8 & 84397.6 & 62692.0 & 57189.7 \\ 53 & \bullet & 28266.8 & 36887.0 & 34813.6 & 52658.5 & 62680.1 & 62112.0 \\ 54 & \bullet & 26779.7 & 37924.5 & 35856.8 & 63731.3 & 60185.1 & 63677.1 \\ 55 & \bullet & 34176.0 & 38727.8 & 36740.0 & 65589.7 & 62063.0 & 64902.5 \\ 56 & \bullet & 32206.4 & 45868.7 & 43446.7 & 79874.7 & 63519.7 & 64419.3 \\ 57 & \bullet & 23931.5 & 43645.0 & 41417.7 & 75851.4 & 77322.7 & 68382.8 \\ 58 & \bullet & 32678.8 & 45843.9 & 43618.1 & 78774.9 & 73624.1 & 68453.7 \\ 59 & \bullet & 42686.3 & 46515.4 & 44853.9 & 79191.2 & 76543.1 & 67545.4 \\ 60 & \bullet & 40215.2 & 54787.4 & 53867.9 & 97473.7 & 77539.7 & 71257.3 \\ 61 & \bullet & 41384.4 & 52956.5 & 50934.1 & 93171.7 & 95693.3 & 75687.0 \\ 62 & \bullet & 40604.3 & 55834.6 & 53664.7 & 79219.0 & 91149.3 & 80393.2 \\ 63 & \bullet & 52263.6 & 54927.1 & 53156.6 & 95532.0 & 95048.8 & 83294.9 \\ 64 & \bullet & 47308.3 & 66803.4 & 63787.7 & 118267 . & 93760.9 & 87392.8 \\ 65 & \bullet & 49532.1 & 62698.5 & 60761.0 & 116008 . & 115971 . & 88923.9 \\ 66 & \bullet & 56141.8 & 63783.3 & 61321.1 & 113315 . & 108070 . & 98972.8 \\ 67 & \bullet & 79873.5 & 64928.1 & 61964.0 & 120670 . & 110853 . & 81984.1 \\ 68 & \bullet & 70476.0 & 78926.7 & 72257.4 & 154800 . & 118106 . & 75172.7 \\ 69 & \bullet & 69199.7 & 73179.9 & 70832.9 & 143656 . & 152131 . & 88282.6 \\ 70 & \bullet & 69595.3 & 74999.0 & 72543.4 & 144199 . & 141309 . & 81977.0 \\ 71 & \bullet & 88632.3 & 79149.7 & 75747.2 & 148745 . & 141743 . & 81409.0 \\ 72 & \bullet & 84501.5 & 107376 . & 102365 . & 196008 . & 145342 . & 82723.4 \\ 73 & \bullet & 88186.5 & 103744 . & 99385.4 & 188246 . & 190998 . & 81083.5 \\ 74 & \bullet & 87806.4 & 111143 . & 106611 . & 199326 . & 184387 . & 81615.9 \\ 75 & \bullet & 52263.6 & 115943 . & 111979 . & 203749 . & 194795 . & 83452.7 \\ 76 & \bullet & 114819 . & 145199 . & 139788 . & 260000 . & 199785 . & 92536.7 \\ 77 & \bullet & 111209 . & 146638 . & 141156 . & 257847 . & 254599 . & 102162 . \\ 78 & \bullet & 118454 . & 152216 . & 146589 . & 270670 . & 252365 . & 189078 . \\ 79 & \bullet & 117208 . & 158389 . & 160841 . & 273596 . & 265043 . & 114838 . \\ 80 & \bullet & 149644 . & 197004 . & 189833 . & 346648 . & 267249 . & 131433 . \\ & & 1 & 2 & 3 & 4 & 5 & 6\end{array}$




$\begin{array}{rrrr} & & \text { M21T } & \text { P21P } \\ 1 & \bullet & 18649.6 & 18239.2 \\ 2 & \bullet & 19157.0 & 18680.8 \\ 3 & \bullet & 19773.7 & 19287.5 \\ 4 & \bullet & 21183.1 & 20776.7 \\ 5 & \bullet & 20971.1 & 22613.4 \\ 6 & \bullet & 21102.8 & 22678.0 \\ 7 & \bullet & 21620.1 & 21210.9 \\ 8 & \bullet & 23525.7 & 23618.2 \\ 9 & \bullet & 22985.2 & 22528.1 \\ 10 & \bullet & 23768.7 & 22751.4 \\ 11 & \bullet & 23988.2 & 23458.7 \\ 12 & \bullet & 26774.1 & 26233.8 \\ 13 & \bullet & 26701.3 & 26154.9 \\ 14 & \bullet & 27308.5 & 26795.3 \\ 15 & \bullet & 28490.8 & 27897.7 \\ 16 & \bullet & 32325.6 & 31727.7 \\ 17 & \bullet & 33119.2 & 32508.9 \\ 18 & \bullet & 33995.8 & 33445.8 \\ 19 & \bullet & 35965.1 & 35338.3 \\ 20 & \bullet & 39865.7 & 39233.6 \\ 21 & \bullet & 41055.5 & 30224.4 \\ 22 & \bullet & 41014.8 & 40249.9 \\ 23 & \bullet & 41640.5 & 41022.5 \\ 24 & \bullet & 46654.6 & 45868.7 \\ 25 & \bullet & 47159.7 & 56334.1 \\ 26 & \bullet & 48276.0 & 47372.6 \\ 27 & \bullet & 49820.7 & 48901.3 \\ 28 & \bullet & 55986.5 & 55043.1 \\ 29 & \bullet & 55503.9 & 54639.7 \\ 30 & \bullet & 57723.6 & 56604.8 \\ 31 & \bullet & 58900.2 & 57944.7 \\ 32 & \bullet & 64829.2 & 63649.3 \\ 33 & \bullet & 65405.7 & 64388.7 \\ 34 & \bullet & 67126.6 & 66210.6 \\ 35 & \bullet & 68513.9 & 67555.7 \\ 36 & \bullet & 74909.5 & 73973.9 \\ 37 & \bullet & 75205.4 & 74162.9 \\ 38 & \bullet & 76661.3 & 75447.6 \\ 39 & \bullet & 75517.7 & 74710.5 \\ 40 & \bullet & 83122.1 & 82153.7 \\ 41 & \bullet & 80369.4 & 78314.3 \\ 42 & \bullet & 81684.7 & 80715.6 \\ 43 & \bullet & 82361.1 & 81385.1 \\ 45 & \bullet & 91229.0 & 89975.5 \\ 46 & \bullet & 88825.6 & 87711.5 \\ & & 89871.9 & 88471.8\end{array}$




$\begin{array}{rrrr} & & \text { M21T } & \text { P21P } \\ 47 & \bullet & 90988.9 & 89418.2 \\ 48 & \bullet & 102203 . & 100823 . \\ 49 & \bullet & 101022 . & 99906.4 \\ 50 & \bullet & 108024 . & 103609 . \\ 51 & \bullet & 108419 . & 107204 . \\ 52 & \bullet & 121517 . & 119870 . \\ 53 & \bullet & 124178 . & 122797 . \\ 54 & \bullet & 127408 . & 125741 . \\ 55 & \bullet & 132489 . & 128422 . \\ 56 & \bullet & 144294 . & 142042 . \\ 57 & \bullet & 144234 . & 142007 . \\ 58 & \bullet & 147229 . & 144997 . \\ 59 & \bullet & 146737 . & 143085 . \\ 60 & \bullet & 168731 . & 166951 . \\ 61 & \bullet & 168059 . & 160836 . \\ 62 & \bullet & 177612 . & 175442 . \\ 63 & \bullet & 178827 . & 177956 . \\ 64 & \bullet & 205660 . & 203364 . \\ 65 & \bullet & 198932 . & 188994 . \\ 66 & \bullet & 204188 . & 201726 . \\ 67 & \bullet & 202854 . & 220990 . \\ 68 & \bullet & 229973 . & 227384 . \\ 69 & \bullet & 231938 . & 229591 . \\ 70 & \bullet & 226176 . & 203720 . \\ 71 & \bullet & 230154 . & 226751 . \\ 72 & \bullet & 278731 . & 273721 . \\ 73 & \bullet & 269329 . & 265470 . \\ 74 & \bullet & 28094.2 & 276410 . \\ 75 & \bullet & 287202 . & 283238 . \\ 76 & \bullet & 352537 . & 347136 . \\ 77 & \bullet & 360009 . & 354528 . \\ 78 & \bullet & 379749 . & 374122 . \\ 79 & \bullet & 388434 . & 382087 . \\ 80 & \bullet & 478081 . & 470911 . \\ & & & \\ & & & \\ 57\end{array}$




\begin{tabular}{|c|c|c|c|c|}
\hline & & RNML & RNMN & RT \\
\hline 1 & - & 6.32000 & 9.00000 & 7.36300 \\
\hline 2 & $\bullet$ & 6.32760 & 9.00000 & 7.44700 \\
\hline 3 & - & 6.41300 & 9.00000 & 7.49700 \\
\hline 4 & $\bullet$ & 6.44880 & 9.00000 & 7.50300 \\
\hline 5 & - & 6.45700 & 9.00000 & 7.53700 \\
\hline 6 & - & 6.54380 & 9.00000 & 7.53700 \\
\hline 7 & - & 6.60700 & 9.00000 & 7.57000 \\
\hline 8 & - & 6.64300 & 9.00000 & 7.59000 \\
\hline 9 & 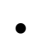 & 6.63700 & 9.00000 & 7.61000 \\
\hline 10 & 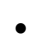 & 6.66000 & 9.00000 & 7.63700 \\
\hline 11 & 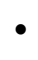 & 6.66700 & 9.00000 & 7.65300 \\
\hline 12 & $e^{\circ}$ & 6.68300 & 9.00000 & 7.88700 \\
\hline 13 & • & 6.75000 & 9.00000 & 7.71300 \\
\hline 14 & - & 6.79000 & 9.00000 & 7.74000 \\
\hline 15 & 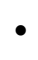 & 6.81700 & 9.00000 & 7.78300 \\
\hline 16 & - & 6.85700 & 9.00000 & 7.76300 \\
\hline 17 & 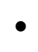 & 6.88700 & 9.00000 & 7.75700 \\
\hline 18 & - & 6.92300 & 9.00000 & 7.76000 \\
\hline 19 & • & 6.95000 & 9.00000 & 7.75000 \\
\hline 20 & - & 6.99300 & 9.00000 & 7.76000 \\
\hline 21 & - & 7.05000 & 9.00000 & 7.75300 \\
\hline 22 & 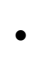 & 7.11300 & 9.00000 & 7.75000 \\
\hline 23 & - & 7.16000 & 9.00000 & 7.75700 \\
\hline 24 & 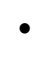 & 7.19700 & 9.00000 & 7.78700 \\
\hline 25 & • & 7.26700 & 9.02300 & 7.81000 \\
\hline 26 & - & 7.31300 & 9.86300 & 7.81000 \\
\hline 27 & - & 7.34000 & 9.10000 & 7.80700 \\
\hline 28 & 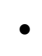 & 7.37000 & 9.13000 & 7.81000 \\
\hline 29 & $\bullet$ & 7.42000 & 9.16000 & 7.81000 \\
\hline 30 & - & 7.46700 & 9.19000 & 7.80700 \\
\hline 31 & - & 7.50000 & 9.22000 & 7.85700 \\
\hline 32 & 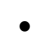 & 7.51700 & 9.23700 & 7.91300 \\
\hline 33 & - & 7.58000 & 9.26000 & 7.94000 \\
\hline 34 & • & 7.57700 & 9.27700 & 7.97000 \\
\hline 35 & - & 7.57000 & 9.28700 & 8.02000 \\
\hline 36 & $\bullet$ & 7.55000 & 9.29700 & 8.06700 \\
\hline 37 & • & 7.57700 & 9.31000 & 8.10000 \\
\hline 38 & - & 7.59700 & 9.31700 & 8.12000 \\
\hline 39 & - & 7.63700 & 10.0070 & 8.15000 \\
\hline 40 & - & 7.66300 & 10.4270 & 8.17000 \\
\hline 41 & 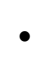 & 7.65700 & 10.4200 & 8.17700 \\
\hline 42 & 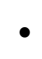 & 7.66700 & 10.4670 & 8.17300 \\
\hline 43 & 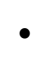 & 7.67700 & 10.4900 & 8.19700 \\
\hline 44 & - & 7.68700 & 10.5070 & 8.21700 \\
\hline 45 & 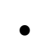 & 7.61700 & 10.0870 & 8.60000 \\
\hline 46 & - & 7.60000 & 9.87000 & 8.84000 \\
\hline
\end{tabular}


LINE 14 TIME SERIES PROCESSOR VEERSION 2.7 FEB. 1977 UNI 1106 SALI PAGE 13

\begin{tabular}{|c|c|c|c|c|}
\hline & & RNML & RNMN & $\mathrm{RT}$ \\
\hline 47 & • & 7.60000 & 9.87000 & 8.74000 \\
\hline 48 & • & 7.59000 & 9.86700 & 8.72700 \\
\hline 49 & • & 7.03300 & 8.85300 & 7.94300 \\
\hline 50 & • & 7.04700 & 8.86000 & 7.95000 \\
\hline 51 & $\bullet$ & 7.06000 & 8.86300 & 7.95300 \\
\hline 52 & • & 7.03700 & 8.87000 & 7.85000 \\
\hline 53 & • & 6.81700 & 8.27300 & 7.53000 \\
\hline 54 & • & 7.10700 & 8.85700 & 7.94300 \\
\hline 55 & $\bullet$ & 7.68000 & 10.0300 & 8.80700 \\
\hline 56 & • & 7.63300 & 10.0600 & 8.79000 \\
\hline 57 & - & 7.63700 & 10.1630 & 8.82700 \\
\hline 58 & $\bullet$ & 7.61300 & 11.0370 & 9.28000 \\
\hline 59 & - & 7.95300 & 11.4900 & 9.56300 \\
\hline 60 & • & 7.52300 & 11.5770 & 9.59300 \\
\hline 61 & • & 7.54300 & 11.6470 & 9.65300 \\
\hline 62 & $\bullet$ & 7.57000 & 11.7000 & 9.72300 \\
\hline 63 & • & 7.58700 & 11.7300 & 9.76000 \\
\hline 64 & • & 7.57700 & 11.7600 & 9.77300 \\
\hline 65 & • & 6.65700 & 11.2630 & 9.11700 \\
\hline 66 & • & 6.64000 & 11.2730 & 9.12700 \\
\hline 67 & $\bullet$ & 6.60000 & 12.0630 & 9.54300 \\
\hline 68 & $\bullet$ & 6.48000 & 12.4770 & 9.87700 \\
\hline 69 & - & 6.49300 & 12.4800 & 9.63700 \\
\hline 70 & • & 6.47000 & 14.1000 & 10.4270 \\
\hline 71 & $\bullet$ & 6.34300 & 14.8870 & 11.2370 \\
\hline 72 & • & 6.22300 & 14.9070 & 11.4570 \\
\hline 73 & $\bullet$ & 6.13700 & 14.9270 & 11.7070 \\
\hline 74 & • & 6.01000 & 14.9370 & 12.0400 \\
\hline 75 & $\bullet$ & 6.00300 & 14.9530 & 12.2370 \\
\hline 76 & $\bullet$ & 6.20700 & 15.0300 & 12.3370 \\
\hline 77 & • & 6.68000 & 15.0700 & 12.4400 \\
\hline 78 & $\bullet$ & 6.82000 & 15.0800 & 12.5100 \\
\hline 79 & • & 7.74300 & 14.9775 & 12.7630 \\
\hline \multirow[t]{2}{*}{80} & - & 9.49300 & 16.3800 & 14.1230 \\
\hline & & 1 & 2 & 3 \\
\hline
\end{tabular}




\begin{tabular}{|c|c|c|c|c|c|}
\hline & TCR & DTC1 & CME & PIB1 & IPCM \\
\hline 1 & 12.1466 & -2.82719 & .286961 & 39493.0 & 98.4790 \\
\hline 2 & 12.1971 & -2.42316 & .269417 & 37926.0 & 97.8510 \\
\hline 3 & 12.3302 & -1.35845 & .265105 & 36061.0 & 98.8270 \\
\hline 4 & 12.4066 & -.747372 & .262739 & 36724.0 & 100.000 \\
\hline 5 & 12.5117 & $.932962-01$ & .237515 & 41440.0 & 100.847 \\
\hline 6 & 12.6822 & .817923 & .233952 & 39796.0 & 101.690 \\
\hline 7 & 12.8362 & 1.08943 & .246147 & 37539.0 & 102.534 \\
\hline 8 & 12.7401 & 1.92055 & .254118 & 30534.0 & 103.377 \\
\hline 9 & 12.7792 & 2.23398 & .238625 & 43376.0 & 104.157 \\
\hline 10 & 12.8460 & 2.76771 & .232233 & 41655.0 & 104.932 \\
\hline 11 & 12.8417 & 2.73383 & .213093 & 39607.0 & 105.709 \\
\hline 12 & 12.9643 & 3.71478 & .199673 & 40334.0 & 106.485 \\
\hline 13 & 13.0223 & 4.17827 & .187622 & 46841.0 & 107.313 \\
\hline 14 & 13.0650 & 4.51962 & .182871 & 44983.0 & 108.136 \\
\hline 15 & 13.1074 & 4.85892 & .185295 & 42771.0 & 108.961 \\
\hline 16 & 13.1494 & 5.19533 & .166020 & 43557.0 & 109.785 \\
\hline 17 & 13.3229 & 6.58333 & .177126 & 52318.0 & 111.354 \\
\hline 18 & 13.4660 & 7.72797 & .162308 & 50242.0 & 112.914 \\
\hline 19 & 13.6085 & 8.86803 & .130489 & 47773.0 & 114.478 \\
\hline 20 & 13.7352 & 9.88125 & .123899 & 48650.0 & 116.039 \\
\hline 21 & 13.7995 & 10.3957 & .122018 & 55711.0 & 116.707 \\
\hline 22 & 13.7315 & 9.85165 & .112971 & 53501.0 & 117.371 \\
\hline 23 & 13.7948 & 10.3583 & .104764 & 50871.0 & 118.037 \\
\hline 24 & 13.7852 & 10.2820 & $.985368-01$ & 51804.0 & 118.702 \\
\hline 25 & 13.7912 & 10.3295 & $913227-01$ & 59672.0 & 119.873 \\
\hline 26 & 13.8102 & 10.4817 & $.829028-01$ & 67209.0 & 121.036 \\
\hline 27 & 13.8013 & 10.4101 & $.763135-01$ & 54397.0 & 122.203 \\
\hline 28 & 13.8622 & 10.8976 & $.727538-01$ & 55395.0 & 123.368 \\
\hline 29 & 13.9210 & 11.3681 & $.720434-01$ & 59839.0 & 124.269 \\
\hline 30 & 13.9090 & 11.2716 & .695594-01 & 59938.0 & 125.165 \\
\hline 31 & 13.8695 & 10.9563 & $.696153-01$ & 59290.0 & 126.063 \\
\hline 32 & 13.8444 & 10.7555 & $.709876-01$ & 62205.0 & 126.959 \\
\hline 33 & 13.7647 & 10.1178 & $.678938-01$ & 67850.0 & 127.719 \\
\hline 34 & 13.6864 & 9.49138 & $.716885-01$ & 64142.0 & 128.475 \\
\hline 35 & 13.6231 & 8.98472 & $.723184-01$ & 63809.0 & 129.233 \\
\hline 36 & 13.5354 & 8.28349 & $.662530-01$ & 65899.0 & 129.990 \\
\hline 37 & 13.4677 & 7.74142 & $.565315-01$ & 71217.0 & 131.284 \\
\hline 38 & 13.3890 & 7.11163 & $.535375-01$ & 69240.0 & 132.571 \\
\hline 39 & 13.3368 & 6.69451 & $.525346-01$ & 65484.0 & 133.860 \\
\hline 40 & 13.2624 & 6.09912 & $.534588-01$ & 71460.0 & 135.143 \\
\hline 41 & 13.2079 & 5.66324 & 496331-01 & 72508.0 & 136.500 \\
\hline 42 & 13.1178 & 4.94227 & $.450328-01$ & 75960.0 & 137.700 \\
\hline 43 & 13.1347 & 5.07736 & $.451172-01$ & 74202.0 & 139.700 \\
\hline 44 & 13.1350 & 5.07985 & .440964-01 & 73929.0 & 141.200 \\
\hline 45 & 13.2617 & 6.09334 & .432957-01 & 82725.0 & 143.400 \\
\hline 46 & 13.2220 & 5.77610 & $.421227-01$ & 76037.0 & 145.000 \\
\hline
\end{tabular}




\begin{tabular}{|c|c|c|c|c|c|c|}
\hline & & TCR & DTC1 & $\mathrm{CME}$ & PIB1 & IPCM \\
\hline 47 & • & 13.2605 & 6.08498 & $.393898-01$ & 71940.0 & 146.500 \\
\hline 48 & $\bullet$ & 13.2752 & 6.20144 & $.327277-01$ & 76698.0 & 147.500 \\
\hline 49 & $\bullet$ & 13.3485 & 6.78827 & $.260773-01$ & 82720.0 & 149.400 \\
\hline 50 & $\bullet$ & 13.4456 & 7.56500 & $.220438-01$ & 83402.0 & 151.700 \\
\hline 51 & $\bullet$ & 13.5197 & 8.15746 & $.206642-01$ & 81727.0 & 154.000 \\
\hline 52 & $\bullet$ & 13.5508 & 8.40656 & $.201486-01$ & 61251.0 & 155.700 \\
\hline 53 & $\bullet$ & 13.6373 & 8.29856 & $.206444-01$ & 97194.0 & 158.600 \\
\hline 54 & $\bullet$ & 13.5393 & 8.31436 & $.211108-01$ & 88238.0 & 161.800 \\
\hline 55 & $\bullet$ & 13.7610 & 10.0878 & $.198631-01$ & 85036.0 & 188.300 \\
\hline 56 & • & 13.9989 & 11.9914 & $.248425-01$ & 90632.0 & 175.000 \\
\hline 57 & $\bullet$ & 14.6096 & 16.8768 & $.255329-01$ & 97305.0 & 188.700 \\
\hline 58 & $\bullet$ & 14.7520 & 18.0162 & $.227291-01$ & 94754.0 & 195.600 \\
\hline 59 & $\bullet$ & 14.8915 & 19.1318 & $.231671-01$ & 91320.0 & 203.900 \\
\hline 60 & $\bullet$ & 15.4708 & 23.7866 & $.222487-01$ & 91620.0 & 217.000 \\
\hline 61 & $\bullet$ & 15.7902 & 26.3213 & $.231171-01$ & 92935.0 & 224.900 \\
\hline 62 & $\bullet$ & 16.4048 & 31.2384 & $.235366-01$ & 102761. & 237.800 \\
\hline 63 & $\bullet$ & 16.6661 & 33.3290 & $.278671-01$ & 98591.0 & 246.100 \\
\hline 64 & $\bullet$ & 16.8685 & 34.9479 & $.332137-01$ & 96013.0 & 253.200 \\
\hline 65 & $\bullet$ & 17.3958 & 39.1667 & $.441458-01$ & 106560. & 263.000 \\
\hline 66 & $\bullet$ & 17.3775 & 39.0199 & $.704557-01$ & 101917. & 266.800 \\
\hline 67 & $\bullet$ & 17.8575 & -9.35274 & $.790685-01$ & 97273.0 & 278.200 \\
\hline 68 & $\bullet$ & 19.5839 & -1.83515 & .114911 & 91050.0 & 308.100 \\
\hline 69 & $\bullet$ & 21.3251 & -6.05676 & .136072 & 103983. & 343.000 \\
\hline 70 & $\bullet$ & 22.0486 & -4.51815 & .182519 & 104748 & 361.800 \\
\hline 71 & $\bullet$ & 23.3986 & 3.07748 & .198519 & 997478. & 368.600 \\
\hline 72 & $\bullet$ & 24.2240 & 6.57301 & .194389 & 101023. & 406.900 \\
\hline 73 & $\bullet$ & 24.9791 & 9.84649 & .181976 & 107301. & 427.700 \\
\hline 74 & • & 25.1762 & 10.3372 & .153903 & 114606. & 443.800 \\
\hline 75 & $\bullet$ & 25.7014 & 13.0476 & .167279 & 110550 & 462.300 \\
\hline 76 & $\bullet$ & 26.0724 & 14.7551 & .173266 & 108143. & 477.700 \\
\hline 77 & $\bullet$ & 26.9556 & 18.0970 & .168429 & 120579 & 508.500 \\
\hline 78 & $\bullet$ & 26.8673 & 17.6325 & .176347 & 120018 & 525.500 \\
\hline 79 & $\bullet$ & 27.0943 & 19.0172 & .215242 & 117302. & 546.500 \\
\hline \multirow[t]{2}{*}{80} & $\bullet$ & 27.6131 & 21.0969 & .242548 & 117949. & 573.200 \\
\hline & & 1 & 2 & 3 & 4 & 5 \\
\hline
\end{tabular}


LINE 17 TIME SERIES PROCESSOR VEERSION 2.7 FEB. 1977 UNI 1106 SALI PAGE 16

\begin{tabular}{|c|c|c|}
\hline & & $\mathrm{DF}$ \\
\hline 52 & • & -4.31940 \\
\hline 53 & • & -1.48240 \\
\hline 54 & • & -1.39820 \\
\hline 55 & • & -1.59760 \\
\hline 56 & • & -19.1944 \\
\hline 57 & • & -7.19090 \\
\hline 58 & - & -2.43200 \\
\hline 59 & • & -5.00220 \\
\hline 60 & • & -2.77910 \\
\hline 61 & • & -1.39100 \\
\hline 62 & • & -.811500 \\
\hline 63 & • & -6.95200 \\
\hline 64 & • & -12.1910 \\
\hline 65 & $\bullet$ & -10.2484 \\
\hline 66 & • & -14.5902 \\
\hline 67 & • & 12.2519 \\
\hline 68 & • & -35.9601 \\
\hline 69 & • & -23.0089 \\
\hline 70 & • & -23.1096 \\
\hline 71 & • & -17.2188 \\
\hline 72 & • & -15.5824 \\
\hline 73 & • & -7.42830 \\
\hline 74 & • & -9.20620 \\
\hline 75 & • & -8.99810 \\
\hline 76 & • & -6.88950 \\
\hline 77 & • & -3.93870 \\
\hline 78 & • & -11.4000 \\
\hline
\end{tabular}




\section{REFERENCIAS}

Baéz, J. (1979), “Estimación de Componentes de la Demanda de Dinero". Trabajo presentado en la XVI Reunión de Técnicos de Bancos Centrales del Continente Americano, San José, Costa Rica, noviembre.

Baliño, T. (1977), “Algunos Resultados sobre la Demanda de Dinero en la Argentina”, Ensayos Económicos, No. 1, marzo.

Banco de México (1977), "Estudios de Moneda y Banca y Política Monetaria sobre México: Selección Bibliográfica 1943-1978”, Subdirección de Investigación Económica.

Baumol, W. (1952), “The Transactions Demand for Cash: An Inventory Theoretic Approach”. Quarterly Journal of Economics, noviembre.

Cambiaso, J. (1978), La Demanda de Dinero en América Latina, CEMLA, Ensayo No. 40.

Feige, E. (1967), "Expectations and Adjustments in the Monetary Sector". American Economic Review, mayo.

Foley, D. (1977), “Three Talks on Monetary Theory”. Conferencia presentada en la UAM, México, D.F. durante el mes de enero (Mimeo).

Friedman, M. (1956), “The Quantity Theory of Money - Aa Restatement” en Studies in the Quantity Theory of Money. Editado por M. Friedman. The University of Chicago Press.

Genel, J.L. (1971), Demanda de Dinero. Tesis profesional, UNAM, México.

Goldfeld, S. (1973), “The Demand for Money Revisited”. Brookings Papers on Economic Activity: 3. (1976), “The Case of the Missing Money”. Brookings Paper on Economic Activity: 3. 
Gómez Oliver, A. (1976), "La Demanda de Dinero en México”. En E.F. Hurtado ed. Cincuenta Años de Banca Central, F.C.E., México.

(1978), Dinero, Inflación y Comercio Exterior en México, CEMLA, México.

Gordon, R. Ed. (1974), Milton Friedman's Monetary Framework. A Debate with his Critics. The University of Chicago Press.

Hafter, W. y S. Hein (1980), "The Dynamics and Estimation of Short-Run Money Demand", Federal Reserve Bank of St. Louis Review, marzo.

Hicks, J. (1974), The Crisis in Keynesian Economics. Basil Blackwell, N. Y.

Intrilligator, M. (1978), Econometric Models, Techniques and Applications. Prentice Hall, N.J.

Johnston, J. (1972), Econometric Models, 2ª Edición. Mc Graw Hill, N.Y.

Laidler, D. (1966), "Some Evidence on the Demand for Money". Journal of Political Economy, diciembre.

(1977), The Demand for Money: Theories and Evidence, $2^{\text {nd }}$. Ed., Harper and Row, N.Y.

Leijonhufvud, A. (1968), On Keynesian Economics and the Economics of Keynes, Oxford University Press.

Meltzer, A. (1963), "The Demand for Money: The Evidence from the Time Series". Journal of Political Economy, junio.

Montemayor, A. (1967), La Demanda de Dinero: El Caso de México. Universidad de Pennsylvania.

Ramírez L. (1977), Expectativas de Devaluación y Demanda de Dinero: El Caso de México en el Período 1947-1957. Tesis profesional, ITAM, México. 
Sargent, T. (1979), Macroeconomic Theory. Academic Press, N.Y.

Tobin, J. (1956), "The Interest Elasticity of the Transactions Demand for Cash". The Review of Economics and Statistics, agosto.

Valdez, G. (1980), “Una Demanda de Dinero para México”. Centro de Estudios Económicos del Sector Privado, A. C.

White, W. (1978), "Improving the Demand for Money under Moderate Inflation". IMF Staff Papers, septiembre.

Zellner, A., D. Huang y L. Chow (1965), "Further Analysis of the Consumption Function with Emphasis on the Role of Liquid Assets", Econometrica, julio. 
BANCO DE MEXICO, S.A.

\section{SUBDIRECCION DE INVESTIGACION ECONOMICA} SERIE DOCUMENTOS DE INVESTIGACION

1. ESTRUCTURA FINANCIERA Y EXPERIENCIA CAMBIARIA: MEXICO 1954-1977. Guillermo Ortíz. Octubre, 1978.

2. EL FINANCIAMIENTO DEL GASTO PUBLICO EN UNA ECONOMIA EN CRECIMIENTO : CASO DE MEXICO. Alain Ize. Noviembre, 1978.

3. ALGUNOS ASPECTOS DEL ENDEUDAMIENTO PUBLICO EXTERNO EN MEXICO. Ernesto Zedillo. Diciembre, 1978.

4. UNA APLICACIÓN DEL MODELO BAYESIANO DE DECISION EN EL ANALISIS DE FUNCIONES DE PRODUCCION AGRICOLA. Héctor E. González M. Diciembre, 1978.

5. POLITICA MACROECONOMICA EN EL CORTO PLAZO: UNA RESEÑA. Alain Ize. Marzo, 1979.

6. ESTUDIOS DE MONEDA Y BANCA Y POLITICA MONETARIA SOBRE MEXICO: SELECCIÓN BIBLIOGRAFICA DE 1943 A 1978. Abril, 1979.

7. COMERCIO EXTERIOR MEXICO - ESTADOS UNIDOS: PROBLEMAS DE COMPARABILIDAD ESTADISTICA. Jorge Carriles Rubio. Mayo, 1979.

8. EXPLOTACION OPTIMA DE RESERVAS PETROLERAS EN UN CONTEXTO MACROECONOMICO. José Córdoba. Mayo, 1979.

9. ASPECTOS DEFLACIONARIOS DE LA DEVALUACION DEL PESO MEXICANO DE 1976. José Córdoba y Guillermo Ortíz. Mayo, 1979.

10. EXTRACCION OPTIMA DE PETROLEO Y ENDEUDAMIENTO EXTERNO: EL CASO DE MEXICO. Ernesto Zedillo. Junio, 1979.

11. IMPUESTOS DIRECTOS: PROGRESIVIDAD OPTIMA. Jesús Seade. Septiembre, 1979.

12. OPCIONES DE POLITICA ECONOMICA 1979 - 1982. Sócrates Rizzo y Leopoldo Solís. Septiembre, 1979.

13. INTERMEDIARIOS FINANCIEROS Y MERCADOS IMPERFECTOS DE CAPITAL. Guillermo Ortíz. Septiembre, 1979. 
14. ESTIMACIONES DE EQUILIBRIO GENERAL DE LOS EFECTOS DE LAS DISTORSIONES EN LOS MERCADOS DE FACTORES: EL CASO DE MEXICO. José J. Sidaoui y Richard H. Sines. Octubre, 1979.

15. UN ANALISIS DE LA INFLACION EN MEXICO. Alain Ize. Octubre, 1979.

16. ANALISIS DE LOS COMPONENTES DEL CAMBIO ESTRUCTURAL CON UN MODELO DE EQUILIBRIO GENERAL, 1970 - 75. José J. Sidaoui y Richard H. Sines. Enero, 1980.

17. TIPOS DE CAMBIO FLOTANTES Y DESLIZ CAMBIARIO: LAS EXPERIENCIAS DE ALGUNOS PAISES EN DESARROLLO. Guillermo Ortíz y Leopoldo Solís. Enero, 1980.

18. UN MODELO DE INFLACION Y CRECIMIENTO EN UNA ECONOMIA CAPITALISTA EN DESARROLLO. Alain Ize. Enero, 1980.

19. CRECIMIENTO E INFLACION: ALTERNATIVAS CAMBIARIAS PARA MEXICO. Guillermo Ortíz y Leopoldo Solís. Febrero, 1980.

20. COMPORTAMIENTO DE LA CAPTACION BANCARIA EN MEXICO. Héctor E. González Méndez. Mayo, 1980.

21. LA ENCUESTA DE TURISMO RECEPTIVO. REPORTE METODOLOGICO. Alberto Vargas Aguayo. Junio, 1980.

22. AJUSTE ESTACIONAL DE UNA SERIE DE TIEMPO MEDIANTE EL USO COMPLEMENTARIO DE METODOS TRADICIONALES Y LA TECNICA DE BOXJENKINS. Gabriel Vera Ferrer y Víctor M. Guerrero. Julio, 1980.

23. DISTRIBUCION DEL FINANCIAMIENTO OTORGADO POR EL SISTEMA BANCARIO MEXICANO A LA BANCA PRIVADA Y MIXTA. Víctor M. Guerrero y Gabriel Vera Ferrer. Julio, 1980.

24. LA MIGRACION INDOCUMENTADA A ESTADOS UNIDOS: UN NUEVO ENFOQUE. Juan Díez Canedo. Julio, 1980.

25. UN MODELO FINANCIERO DE DESEQUILIBRIO A CORTO PLAZO PARA LA ECONOMIA MEXICANA. Alain Ize. Julio, 1980.

26. ESTIMACION DE LA FUNCION DE IMPORTACIONES PARA MEXICO. Javier Salas. Agosto, 1980.

27. UNA ALTERNATIVA PARA LA MEDIA ARITMETICA EN EL CALCULO DE PROMEDIOS SIMPLES DE RELATIVOS DE PRECIOS: LA MEDIA GEOMETRICA. Gabriel Vera Ferrer y Víctor M. Guerrero. Agosto, 1980. 
28. LA DEMANDA DE DINERO EN MEXICO: PRIMERAS ESTIMACIONES. Guillermo Ortíz. Septiembre, 1980. 